\title{
MOEA/D based probabilistic PBI approach for risk- based optimal operation of hybrid energy system with intermittent power uncertainty
}

\author{
Huifeng Zhang, IEEE member, Dong Yue*, IEEE Senior member, Wenbin Yue, Kang Li, IEEE Senior member, \\ Mingjia Yin \\ (Institute of advanced technology, Nanjing University of Posts and Telecommunications, Nanjing, 210023, China \\ Jiangsu Engineering Laboratory of Big Data Analysis and Control for Active Distribution Network, 210023, China \\ Department of Computer Science, Brunel University London, Uxbridge, Middlesex UB8 3PH, UK \\ School of Electronic \& Electrical Engineering, University of Leeds, England, LS2 9JT, UK)
}

\begin{abstract}
The stochastic nature of intermittent energy resources has brought significant challenges to the optimal operation of hybrid energy systems. This paper proposes a probabilistic multi-objective evolutionary algorithm based on decomposition (MOEA/D) method with two-step risk-based decision-making strategy to tackle this problem. A scenario based technique is first utilized to generate a stochastic model of the hybrid energy system. Those scenarios divide the feasible domain into several regions. Then, based on the MOEA/D framework, a probabilistic penalty-based boundary intersection (PBI) with gradient descent differential evolution (GDDE) algorithm is proposed to search the optimal scheme from these regions under different uncertainty budgets. To ensure reliable and low risk operation of the hybrid energy system, the Markov inequality is employed to deduce a proper interval of the uncertainty budget. Further, a fuzzy grid technique is proposed to choose the best scheme for real-world applications. Experimental results confirm that the probabilistic adjustable parameters can properly control the uncertainty budget and lower the risk probability. Further, it is also shown that the proposed MOEA/D-GDDE can significantly enhance the optimization efficiency.
\end{abstract}

Keywords- stochastic characteristics, intermittent energy resources, multi-objective optimization, penalty based boundary intersection

\section{INTRODUCTION}

The increasing penetration of renewable energy resources imposes significant challenges on the optimal operation of hybrid energy systems, an important issue in modern electric power systems. The main goal of hybrid energy system management is to schedule the power generation for each generator to minimize the economic cost or to maximize the economic benefit. As environmental problems are drawing increasing global concerns, adequate electricity is not only required at the cheapest possible price, but also at the minimum level of pollutions [1].

H. Zhang and D.Yue are with the institute of Advanced Technology, Nanjing University of Posts and Telecommunications, Jiangsu Province, China, 210023.(zhanghuifeng_520@163.com; medongy@vip.163.com).W. Yue is with Brunel University London, London, U.K.. K. Li and M. Yin is with school of electronic \& electrical Engineering, University of Leeds, U.K.
Thus, the optimal operation of hybrid energy systems becomes a multi-objective optimization problem (MOP), and many multi-objective evolutionary algorithms (MOEAs) have been proposed to produce a set of non-dominant schemes for decision-making, such as non-dominated sorting genetic algorithm (NSGA-II) [2, 3], niched Pareto genetic algorithm (NPGA) [4], strength Pareto evolutionary algorithm (SPEA) [5], multi-objective particle swarm optimization (MOPSO) [6], and multi-objective differential evolution (MOHDE) [7], etc. These MOEAs mainly adopt Pareto-dominance-based approaches, which determines the priority of evolutionary individuals with the Paretodominance order [8]. MOEAs can be broadly classified into three categories [9]: (1) the Pareto-dominance-based approaches $[10,11]$; (2) the indicator-based approaches [12, 13]; (3) the decomposition-based approaches [14, 15]. The MOEA/D mainly optimizes an MOP by decomposing it into several scalar subproblems and optimizing them coordinately in a single run [15]. Each agent is assigned to a different subproblem, and coordinates with other agents to improve the search ability of MOEA/D. Generally, there are three commonly used MOEA/Ds [16, 17]: (1) the weighted sum approach; (2) the weighted Tchebycheff approach; (3) the PBI approach. However, the weighted sum approach cannot properly optimize a non-convex Pareto front, the weighted Tchebycheff approach has difficulties to obtain smooth objective when it deals with non-convex Pareto front, and the efficiency of PBI approach depends on appropriate weight vectors [18]. To overcome the aforementioned problems, [18] imposes constraints on subproblems, and adaptively adjust the constraint during the search process.

Stochastic or uncertainty of intermittent energy resources is the key issue to handle for optimal operation of hybrid energy system management [19, 20]. Currently, it mainly includes three approaches: (1) fuzzy programming; (2) robust optimization; (3) stochastic optimization. [21] presents an interesting risk-based scheduling strategy using a fuzzy method to model the uncertainty of wind power generation. [22] has established a fuzzy-based energy and reserve co-optimization model considering the high penetration of renewable energy. [23] proposes a robust optimization approach that considers the uncertainty of wind 
power output and demand response. [24] presents a new framework using adaptive robust optimization for economic dispatch with high level of wind penetration. However, the choice of fuzzy membership values can be subjective, which cannot ensure the accuracy of the obtained value $[25,26]$. Robust optimization (RO) generally does not consider the accuracy of the system model, tends to be conservative when calculating the optimal value at the minimum risk. Stochastic optimization (SO) has some advantages in accounting for uncertainty and risks [27]. For decreasing optimization conservation, this paper utilizes flexible parameters to split the output of intermittent energy resources into several intervals, scenarios are generated for simulating stochastic process caused by intermittent energy resources with probabilistic characteristics of each interval, and further to acquire stochastic information of each scenario under different uncertainty budgets. This thus provides the probabilistic domain for the proposed probabilistic PBI optimization approach. Simultaneously, to ensure robustness or to avoid possible risks caused by intermittent energy resources, two-step decision-making approach establishes proper uncertainty budget for controlling the disturbance of intermittent energy resources, based on which the best optimal scheme can be selected with the aid of a grid-based decision-making method. The main technical contributions can be concluded as follows:

(1) Scenario based technique is employed to build a hybrid energy system model with different uncertainty budgets. It divides intermittent output range into several probabilistic intervals, and flexible parameters are utilized to adjust uncertainty of different scenarios.

(2) On the basis of the MOEA/D framework, a probabilistic PBI approach is proposed to solve the optimal operation problem of hybrid energy systems, gradient descent based differential evolution (GDDE) is integrated into the optimization framework to enhance the search ability.

(3) To minimize the possible operational risks of hybrid energy systems, a two-step decision-making approach is proposed to deduce proper uncertainty budget with Markov inequality, and then to select the best scheduling scheme from the non-dominated set assisted with a fuzzy grid-based mechanism.

The remainder of this paper is organized as follows: Section II presents the problem formulation. Section III establishes the probabilistic PBI method with generated scenarios. In section IV, two-step decision-making approach is proposed. Section $\mathrm{V}$ presents the experimental results and Section VI concludes the paper.

\section{PROBLEM FORMULATION OF THE STOCHASTIC HYBRID ENERGY SYSTEM}

A. Intermittent power generation with uncertainty budget

To properly handle the uncertainty issue of intermittent energy resources, the intermittent power output $\mathrm{P}_{\mathrm{Ijt}}$ can be described as follows with adjustable intervals [28]:

$$
\left\{\begin{array}{l}
\mathrm{P}_{\mathrm{Ijt}} \in\left[\overline{\mathrm{P}}_{\mathrm{Ijt}}+\gamma_{\mathrm{Ijt}} \tilde{\mathrm{P}}_{\mathrm{Ijt}}^{\min }, \overline{\mathrm{P}}_{\mathrm{Ijt}}+\gamma_{\mathrm{Ijt}} \tilde{\mathrm{P}}_{\mathrm{Ijt}}^{\max }\right] \\
\gamma_{\mathrm{Ijt}} \in[0,1]
\end{array}\right.
$$

where $\overline{\mathrm{P}}_{\mathrm{Ijt}}$ is the forecasted output of the intermittent power, $\tilde{\mathrm{P}}_{\mathrm{Ijt}}^{\min }, \tilde{\mathrm{P}}_{\mathrm{Ijt}}^{\max }$ are the lower and upper limits of deviation, and $\gamma_{\mathrm{Ijt}}$ is the adjustable parameter. Since the power generation forecasting of intermittent energy resources is described with probabilistic intervals, the probability of each obtained intervals is also taken into consideration. To properly analyze the uncertainty budget, the interval in formula (1) can be divided into several levels with different adjustable parameters $\gamma_{\mathrm{Ijt}}$, which satisfies $\gamma_{\mathrm{Ijt}} \in\{0,1 / 4,1 / 2,3 / 4,1\}$ and $\tilde{\mathrm{P}}_{\mathrm{wj}, \mathrm{t}}^{\min }=-\tilde{\mathrm{P}}_{\mathrm{wj}, \mathrm{t}}^{\max }$. The deviation of actual output and forecasted output and its probability is illustrated in Fig.1.

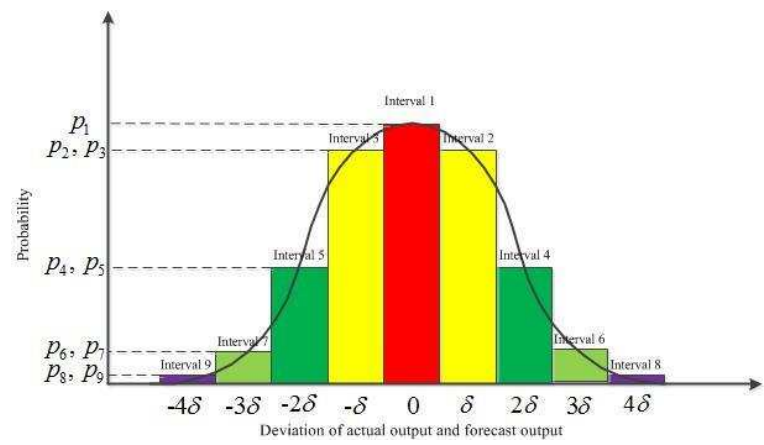

Fig 1 The division of output deviations between actual output and forecasted output

The probability of each interval can be calculated as follows:

$$
\left\{\begin{array}{l}
\mathrm{p}_{1}=\operatorname{Prob}\left(\overline{\mathrm{P}}_{\mathrm{Ijt}}-\delta / 2 \leq \mathrm{P}_{\mathrm{Ijt}} \leq \overline{\mathrm{P}}_{\mathrm{Ijt}}+\delta / 2\right) \\
\mathrm{p}_{2}=\left(\operatorname{Prob}\left(\overline{\mathrm{P}}_{\mathrm{Ijt}}-3 \delta / 2 \leq \mathrm{P}_{\mathrm{Ijt}} \leq \overline{\mathrm{P}}_{\mathrm{Ijt}}+3 \delta / 2\right)-\mathrm{p}_{1}\right) / 2 \\
\mathrm{p}_{4}=\left(\operatorname{Prob}\left(\overline{\mathrm{P}}_{\mathrm{Ijt}}-5 \delta / 2 \leq \mathrm{P}_{\mathrm{Ijt}} \leq \overline{\mathrm{P}}_{\mathrm{Ijt}}+5 \delta / 2\right)-2 \mathrm{p}_{2}-\mathrm{p}_{1}\right) / 2 \\
\mathrm{p}_{6}=\left(\operatorname{Prob}\left(\overline{\mathrm{P}}_{\mathrm{Ijt}}-7 \delta / 2 \leq \mathrm{P}_{\mathrm{Ijt}} \leq \overline{\mathrm{P}}_{\mathrm{Ijt}}+7 \delta / 2\right)-2 \mathrm{p}_{4}-2 \mathrm{p}_{2}-\mathrm{p}_{1}\right) / 2 \\
\mathrm{p}_{8}=\left(\operatorname{Prob}\left(\overline{\mathrm{P}}_{\mathrm{Ijt}}-9 \delta / 2 \leq \mathrm{P}_{\mathrm{Ijt}} \leq \overline{\mathrm{P}}_{\mathrm{Ijt}}+9 \delta / 2\right)-2 \mathrm{p}_{6}-2 \mathrm{p}_{4}-2 \mathrm{p}_{2}-\mathrm{p}_{1}\right) / 2
\end{array}\right.
$$

where $\delta$ represents the deviation unit, $\operatorname{Prob}(\bullet)$ is the probability of the interval, $\mathrm{p}_{2}=\mathrm{p}_{3}, \mathrm{p}_{4}=\mathrm{p}_{5}, \mathrm{p}_{6}=\mathrm{p}_{7}$ and $\mathrm{p}_{8}=\mathrm{p}_{9}$. The uncertainty budget $\Delta_{\mathrm{t}}$ is utilized to control the uncertainty degree of intermittent energy resources, which is allocated for intermittent power generation as [28]:

$$
\sum_{\mathrm{j}=1}^{\mathrm{N}_{\mathrm{I}}} \gamma_{\mathrm{Ijt}} \leq \Delta_{\mathrm{t}}
$$

where $\mathrm{N}_{I}$ is the number of intermittent energy resources, and the uncertainty budget $\Delta_{\mathrm{t}}$ is in the range $\left[0, \mathrm{~N}_{\mathrm{I}}\right]$. It can be satisfied with adjusting those parameters, which determines the amplitude of output disturbance in each intermittent energy resource. If the adjustable parameters are continuous, the probability of formula (3) can be formulated as: 


$$
\begin{aligned}
& \mathrm{P}\left(\sum_{\mathrm{j}=1}^{\mathrm{N}_{\mathrm{I}}} \gamma_{\mathrm{Ijt}} \leq \Delta_{\mathrm{t}}\right)=\iint_{\sum_{\mathrm{j}=1}^{\mathrm{N}_{\mathrm{I}}} \gamma_{\mathrm{Ijt}} \leq \Delta_{\mathrm{t}}} \mathrm{f}\left(\gamma_{\mathrm{Ilt}}, \gamma_{\mathrm{I} 2 \mathrm{t}}, \ldots, \gamma_{\mathrm{IN}_{\mathrm{I}} \mathrm{t}}\right) \\
& \mathrm{d} \gamma_{\mathrm{IIt}} \mathrm{d} \gamma_{\mathrm{I} 2 \mathrm{t}} \cdots \mathrm{d} \gamma_{\mathrm{IN}_{\mathrm{I}} \mathrm{t}}
\end{aligned}
$$

where $f(\bullet)$ represents probability density function (PDF) of the intermittent power generation. The uncertainty budget can be adjusted to control the potential risk caused by the power generation uncertainty, and different combinations of adjustable parameters $\gamma_{\mathrm{Ijt}}$ can achieve certain uncertainty budget.

\section{B. Problem formulation}

A hybrid energy system may consist of energy storage (ES), thermal power and intermittent power (mainly wind power and photovoltaic power), and all energy resources cooperate together to achieve the minimum economic cost and pollutant emissions. The economic cost is mainly caused by the operation cost of ES and fuel cost of thermal power generations. Since scenario-based approach can improve dispatch performance while guaranteeing a quantifiable risk level [29], which can be more suitable for optimal operation especially with considering potential risk, scenario based approach is utilized instead of Monte Carlo method. On the basis of generated scenarios, the economic cost can be expressed as follows:

$$
\left\{\begin{array}{l}
\min \mathrm{F}_{1}=\sum_{\mathrm{s} \in \mathrm{N}_{\mathrm{s}}} \operatorname{Pr}(\mathrm{s})\left(\mathrm{f}_{\mathrm{ES}}(\mathrm{s})+\mathrm{f}_{\text {The }}^{(1)}(\mathrm{s})\right) \\
\mathrm{f}_{\mathrm{ES}}=\sum_{\mathrm{t}=1}^{\mathrm{T}} \sum_{1 \in \mathrm{N}_{\mathrm{l}}} \mathrm{c}_{\mathrm{ops}, \mathrm{l}} \mathrm{P}_{1, \mathrm{t}}^{\mathrm{B}} \\
\mathrm{f}_{\text {The }}^{(1)}(\mathrm{s})=\sum_{\mathrm{t}=1}^{\mathrm{T}} \sum_{\mathrm{i} \in \mathrm{N}_{\mathrm{c}}}\left[\mathrm{a}_{\mathrm{i}}+\mathrm{b}_{\mathrm{i}} \mathrm{P}_{\text {cits }}+\mathrm{c}_{\mathrm{i}} \mathrm{P}_{\text {cits }}^{2}+\left|\mathrm{d}_{\mathrm{i}} \sin \left(\mathrm{e}_{\mathrm{i}}\left(\mathrm{P}_{\mathrm{ci} \text {,min }}-\mathrm{P}_{\text {cits }}\right)\right)\right|\right]
\end{array}\right.
$$

where $\mathrm{N}_{\mathrm{s}}$ represents the total scenario number, $\operatorname{Pr}(\mathrm{s})$ is the probability of scenario $\mathrm{s}, \mathrm{T}$ is the length of the operation period, $\mathrm{N}_{\mathrm{c}}$ is the number of thermal units, $\mathrm{N}_{1}$ is the number of energy storage, $a_{i}, b_{i}, c_{i}, d_{i}, e_{i}$ are the coefficients of fuel cost for thermal power generation, $\mathrm{P}_{\text {cits }}$ and $\mathrm{P}_{\mathrm{ci} \text {,min }}$ are the output and minimum output of thermal unit, $c_{o p s, 1}$ is the cost efficient of 1 th energy storage, $P_{1, t}^{B}$ denotes the charging or discharging output of energy storage respectively. Further, the pollutant emissions from thermal units should be minimized. Similarly, pollutant emission can be formulated as:

$$
\left\{\begin{array}{l}
\min \mathrm{F}_{2}=\sum_{\mathrm{s} \in \mathrm{N}_{\mathrm{s}}} \operatorname{Pr}(\mathrm{s}) \mathrm{f}_{\mathrm{The}}^{(2)}(\mathrm{s}) \\
\mathrm{f}_{\text {The }}^{(2)}(\mathrm{s})=\sum_{\mathrm{t}=1}^{\mathrm{T}} \sum_{\mathrm{i} \in \mathrm{N}_{\mathrm{c}}}\left(\alpha_{1 \mathrm{i}}+\alpha_{2 \mathrm{i}} \mathrm{P}_{\text {cits }}+\alpha_{3 \mathrm{i}} \mathrm{P}_{\text {cits }}^{2}+\alpha_{4 \mathrm{i}} \exp \left(\alpha_{5 \mathrm{i}} \mathrm{P}_{\text {cits }}\right)\right)
\end{array}\right.
$$

where $\alpha_{1 \mathrm{i}}, \alpha_{2 \mathrm{i}}, \alpha_{3 \mathrm{i}}, \alpha_{4 \mathrm{i}}, \alpha_{5 \mathrm{i}}$ are the coefficients of emission rate for thermal power generation.

\section{Constraints}

(1) System load balance:

$$
\sum_{i \in N_{c}} P_{\text {cits }}+\sum_{j \in N_{w}} P_{w j t s}+\sum_{k \in N_{p}} P_{p k t s}+\sum_{1 \in N_{b}} P_{1, t}^{B}=P_{D, t}
$$

where $\mathrm{P}_{\text {wjts }}, \mathrm{P}_{\mathrm{pkts}}$ describe power output of wind power and solar power, $\mathrm{P}_{1, \mathrm{t}}^{\mathrm{B}}$ denotes charge or discharge output of battery energy storage, $\mathrm{N}_{\mathrm{w}}, \mathrm{N}_{\mathrm{p}}, \mathrm{N}_{\mathrm{b}}$ are the index sets of wind farms, $\mathrm{PV}$ arrays and batteries, $\mathrm{P}_{\mathrm{D}, \mathrm{t}}$ is system load demand and transmission loss.

(2) Power generation limits:

$$
\left\{\begin{array}{l}
\mathrm{P}_{\mathrm{ci}, \min } \leq \mathrm{P}_{\mathrm{cits}} \leq \mathrm{P}_{\mathrm{ci}, \max }, \mathrm{i}=1,2, \ldots, \mathrm{N}_{\mathrm{c}} \\
\operatorname{Prob}\left(\mathrm{P}_{\mathrm{wj}, \text { min }} \leq \mathrm{P}_{\mathrm{wjts}} \leq \mathrm{P}_{\mathrm{wj}, \max }\right)=\rho_{\mathrm{w}}, \mathrm{j}=1,2, \ldots, \mathrm{N}_{\mathrm{w}} \\
\operatorname{Prob}\left(\mathrm{P}_{\mathrm{pk}, \min } \leq \mathrm{P}_{\mathrm{pkts}} \leq \mathrm{P}_{\mathrm{pk}, \max }\right)=\rho_{\mathrm{p}}, \mathrm{k}=1,2, \ldots, \mathrm{N}_{\mathrm{p}}
\end{array}\right.
$$

where $\mathrm{P}_{\mathrm{c} \text {, max }}$ is the maximum output of thermal power, $\mathrm{P}_{\mathrm{wj}, \min }, \mathrm{P}_{\mathrm{wj}, \max }$ are the minimum and maximum output of wind power, $\mathrm{P}_{\mathrm{pk}, \min }, \mathrm{P}_{\mathrm{pk}, \max }$ are the minimum and maximum output of solar power, $\rho_{\mathrm{w}}, \rho_{\mathrm{p}}$ are the required probability of wind power and $\mathrm{PV}$ power generation.

(3) Ramp rate limits: During the power generation process, power output can be adjusted within limited condition due to the power generation capacity.

$$
\left\{\begin{array}{l}
\mathrm{DR}_{\mathrm{ci}} \leq \mathrm{P}_{\mathrm{cits}}-\mathrm{P}_{\mathrm{ci}, \mathrm{t}-1, \mathrm{~s}} \leq \mathrm{UR}_{\mathrm{c}}, \mathrm{i}=1,2, \ldots, \mathrm{N}_{\mathrm{c}}, \mathrm{t}=1,2, \ldots, \mathrm{T} \\
\mathrm{DR}_{\mathrm{wj}} \leq \mathrm{P}_{\mathrm{wjts}}-\mathrm{P}_{\mathrm{wj}, \mathrm{t}-1, \mathrm{~s}} \leq \mathrm{UR}_{\mathrm{wj}}, \quad \mathrm{j}=1,2, \ldots, \mathrm{N}_{\mathrm{w}}, \mathrm{t}=1,2, \ldots, \mathrm{T} . \\
\mathrm{DR}_{\mathrm{pk}} \leq \mathrm{P}_{\mathrm{pkts}}-\mathrm{P}_{\mathrm{pk}, \mathrm{t}-1, \mathrm{~s}} \leq \mathrm{UR}_{\mathrm{pk}}, \mathrm{k}=1,2, \ldots, \mathrm{N}_{\mathrm{p}}, \mathrm{t}=1,2, \ldots, \mathrm{T}
\end{array}\right.
$$

where $\mathrm{DR}_{\mathrm{ci}}, \mathrm{UR}_{\mathrm{ci}}$ are the down and up ramp rate limits of thermal power generator, $\mathrm{DR}_{\mathrm{wj}}, \mathrm{UR}_{\mathrm{wj}}$ are the down and up ramp rate limits of wind power, $\mathrm{DR}_{\mathrm{pk}}, \mathrm{UR}_{\mathrm{pk}}$ are the down and up ramp rate limits of solar power.

(4) Wind speed and its PDF: The wind power generation is mainly related to the wind speed, suppose that the wind speed follows the Weibull distribution function, the distribution function of wind power can also be deduced [30]:

$$
\begin{gathered}
\mathrm{P}_{\mathrm{wjts}}=\left\{\begin{array}{cc}
0, & \mathrm{v}_{\mathrm{j}}<\mathrm{v}_{\mathrm{j}, \text { in }} \text { or } \mathrm{v}_{\mathrm{j}} \geq \mathrm{v}_{\mathrm{j}, \text { out }} \\
\mathrm{P}_{\mathrm{wj}, \text { max }} * \frac{\mathrm{v}_{\mathrm{j}}-\mathrm{v}_{\mathrm{j}, \text { in }}}{\mathrm{v}_{\mathrm{j}, \text { rate }}-\mathrm{v}_{\mathrm{j}, \text { in }}}, & \mathrm{v}_{\mathrm{j}, \text { in }} \leq \mathrm{v}_{\mathrm{j}}<\mathrm{v}_{\mathrm{j}, \text { rate }} \\
\mathrm{P}_{\mathrm{wj} \text {,max }}, & \mathrm{v}_{\mathrm{j}, \text { rate }} \leq \mathrm{v}_{\mathrm{j}}<\mathrm{v}_{\mathrm{j}, \text { out }}
\end{array}\right. \\
\mathrm{F}\left(\mathrm{P}_{\mathrm{wjts}}\right)=1-\exp \left\{-\left[\left(1+\frac{\mathrm{v}_{\text {rate }}-\mathrm{v}_{\text {in }}}{\mathrm{v}_{\text {in }} \mathrm{P}_{\mathrm{rate}}} \mathrm{P}_{\mathrm{wjts}}\right) \frac{\mathrm{v}_{\text {in }}}{\mathrm{c}}\right]^{\mathrm{k}}\right\}+ \\
\exp \left[-\left(\mathrm{v}_{\text {out }} / \mathrm{c}\right)^{\mathrm{k}}\right], \quad 0 \leq \mathrm{P}_{\mathrm{wjts}}<\mathrm{P}_{\mathrm{rate}}
\end{gathered}
$$


where $v_{j}$ represents wind speed, $v_{j, \text { in }}, v_{j, \text { rate }}, v_{j, \text { out }}$ denotes the cut-in, rated and cut-out wind speeds. $\mathrm{k}, \mathrm{c}$ are scaling parameters.

(5) The PDF of photovoltaic power: Since photovoltaic power can also be taken as intermittent energy resource, it can be described in probabilistic forms. Generally, the PDF of photovoltaic power output $\eta_{\mathrm{j}}$ can be presented with Beta distribution as follows:

$$
\mathrm{f}\left(\eta_{\mathrm{j}}\right)=\frac{1}{\mathrm{~B}(\alpha, \beta)} \eta_{\mathrm{j}}^{\alpha-1}\left(1-\eta_{\mathrm{j}}\right)^{\beta-1}, \quad 0 \leq \eta_{\mathrm{j}} \leq 1
$$

where $\mathrm{B}(\alpha, \beta)$ represents Beta function with two parameters.

(6) Battery energy storage system (BESS) is also taken into consideration to complement the intermittent energy resources, and its energy management needs to satisfy:

$$
\left\{\begin{array}{l}
\mathrm{V}_{1, \mathrm{t}+1}^{\mathrm{B}}=\mathrm{V}_{1, \mathrm{t}}^{\mathrm{B}}+\eta_{1} \mathrm{P}_{1, \mathrm{t}}^{\mathrm{B}} * \Delta \mathrm{t} \\
\mathrm{V}_{1, \text { min }}^{\mathrm{B}} \leq \mathrm{V}_{1, \mathrm{t}}^{\mathrm{B}} \leq \mathrm{V}_{1, \text { max }}^{\mathrm{B}} \\
\mathrm{P}_{1, \mathrm{t}}^{\mathrm{B}}=\mathrm{P}_{1, \mathrm{t}}^{\text {dis }}, \text { if } \mathrm{P}_{1, \mathrm{t}}^{\mathrm{B}} \geq 0 \\
\mathrm{P}_{1, \mathrm{t}}^{\mathrm{B}}=-\mathrm{P}_{1, \mathrm{t}}^{\text {cha }}, \text { if } \mathrm{P}_{1, \mathrm{t}}^{\mathrm{B}}<0 \\
0 \leq \mathrm{P}_{1, \mathrm{t}}^{\text {dis }} \leq \mathrm{P}_{1, \text { max }}^{\text {dis }} \\
0 \leq \mathrm{P}_{1, \mathrm{t}}^{\text {cha }} \leq \mathrm{P}_{1, \text { max }}^{\text {cha }}
\end{array}\right.
$$

where $\mathrm{P}_{1, t}^{\mathrm{dis}}, \mathrm{P}_{1, \mathrm{t}}^{\text {cha }}$ are the output of discharging and charging state, $\mathrm{P}_{1, \text { max }}^{\text {dis }}, \mathrm{P}_{1, \text { max }}^{\text {cha }}$ are the maximum discharging and charging output in the 1 th battery at $t$ th time period. The state of charge (SOC) is also taken into consideration, $V_{1, t}^{B}$ is the storage of the 1 th battery at $t$ th time period, $V_{1, \min }^{\mathrm{B}}, \mathrm{V}_{1, \max }^{\mathrm{B}}$ are the minimum and maximum storage of the 1 th battery, $\eta_{1} \in(0,1]$ represents the efficiency of SOC.

\section{(7) Minimum on/off time constraints:}

$$
\left\{\begin{array}{l}
{\left[\mathrm{T}_{\mathrm{i}, \mathrm{t}-1}^{\mathrm{R}}-\mathrm{T}_{\mathrm{i}, \min }^{\mathrm{R}}\right]\left[\tau_{\mathrm{i}, \mathrm{t}-1}-\tau_{\mathrm{i}, \mathrm{t}}\right] \geq 0} \\
{\left[\mathrm{~T}_{\mathrm{i}, \mathrm{t}-1}^{\mathrm{S}}-\mathrm{T}_{\mathrm{i}, \min }^{\mathrm{S}}\right]\left[\tau_{\mathrm{i}, \mathrm{t}}-\tau_{\mathrm{i}, \mathrm{t}-1}\right] \geq 0}
\end{array}\right.
$$

where $\mathrm{T}_{\mathrm{i}, \mathrm{t}-1}^{\mathrm{R}}, \mathrm{T}_{\mathrm{i}, \mathrm{t}-1}^{\mathrm{S}}$ denotes continuous the online and offline time of the unit until period $\mathrm{t}-1, \tau_{\mathrm{i}, \mathrm{t}}$ is a binary decision variable for online state of thermal unit at period $\mathrm{t}$.

(8) The spinning reserve constraint:

$$
\begin{aligned}
& \sum_{\mathrm{i} \in \mathrm{N}_{\mathrm{c}}}\left(\mathrm{P}_{\mathrm{ci}, \max }-\mathrm{P}_{\mathrm{ci}, \mathrm{t}}\right)+\sum_{1 \in \mathrm{N}_{\mathrm{l}}}\left(\mathrm{P}_{1, \max }^{\mathrm{dis}}-\mathrm{P}_{1, \mathrm{t}}^{\mathrm{dis}}\right) \\
& \geq \sum_{\mathrm{j} \in \mathrm{N}_{\mathrm{I}}} \gamma_{\mathrm{Ijt}}\left(\tilde{\mathrm{P}}_{\mathrm{Ijt}}^{\mathrm{max}}-\tilde{\mathrm{P}}_{\mathrm{Ijt}}^{\mathrm{min}}\right)
\end{aligned}
$$

Considering the stability of a hybrid energy resource system, it requires more additional power to prevent the disturbance caused by intermittent power uncertainty.

(9) The uncertainty budget. As it is presented in formula (3), the uncertainty budget $\Delta_{\mathrm{t}}$ is taken as rough constraint limit, the summation of adjustable parameters cannot exceed this limit. With consideration of required reliability of hybrid energy system, it needs decision-making strategy to deduce the minimum deviation with utopia uncertainty budget.

\section{THE MOEA/D WITH PENALTY-BASED BOUNDARY INTERSECTION APPROACH}

MOEA/D, originally proposed by Zhang [15], mainly decomposes an MOP into several scalar optimization subproblems, and each subproblem coordinates its neighborhoods to seek the optimal solution. Generally, MOEA/D can be regarded as an improved framework of cMODE proposed in [31]. Generally, an MOP can be stated as follows:

$$
\left\{\begin{array}{l}
\min F(x)=\left(f_{1}(x), f_{2}(x), \ldots, f_{m}(x)\right)^{T} \\
\text { s.t } h_{j}(x) \leq 0, x \in R^{n}, j=1,2, \ldots, J
\end{array}\right.
$$

Since $h_{j}(x)$ are continuous functions, (16) can be considered as a continuous MOP. The decomposition approach involves weight vector $\lambda^{\mathrm{i}}=\left(\lambda_{1}^{\mathrm{i}}, \lambda_{2}^{\mathrm{i}}, \ldots, \lambda_{\mathrm{m}}^{\mathrm{i}}\right)^{\mathrm{T}}$ for the $i$ th subproblem $\left(\sum_{\mathrm{j}=1}^{\mathrm{m}} \lambda_{\mathrm{j}}^{\mathrm{i}}=1, \lambda_{\mathrm{j}}^{\mathrm{i}} \geq 0\right)$. Suppose that $\mathrm{z}^{*}=\left(\mathrm{z}_{1}^{*}, \mathrm{z}_{2}^{*}, \ldots, \mathrm{z}_{\mathrm{m}}^{*}\right)^{\mathrm{T}}$ is a utopian point, then the PBI approach can decompose (10) into several subproblems as follows:

$$
\begin{aligned}
& \min \mathrm{g}^{\mathrm{pbi}}\left(\mathrm{x} \mid \lambda^{\mathrm{i}}, \mathrm{z}^{*}\right)=\mathrm{d}_{1}^{\mathrm{i}}+\beta \mathrm{d}_{2}^{\mathrm{i}} \\
& \mathrm{d}_{1}^{\mathrm{i}}=\left\|\left(\mathrm{F}(\mathrm{x})-\mathrm{z}^{*}\right)^{\mathrm{T}} \lambda^{\mathrm{i}}\right\| /\left\|\lambda^{\mathrm{i}}\right\| \\
& \mathrm{d}_{2}^{\mathrm{i}}=\left\|\mathrm{F}(\mathrm{x})-\mathrm{z}^{*}-\mathrm{d}_{1}^{\mathrm{i}} \lambda^{\mathrm{i}}\right\| \\
& \text { s.t } \mathrm{h}_{\mathrm{j}}(\mathrm{x}) \leq 0, \mathrm{x} \in \mathrm{R}^{\mathrm{n}}, \mathrm{j}=1,2, \ldots, \mathrm{J}
\end{aligned}
$$

where $d_{1}^{i}$ represents the distance between $z^{*}$ and projection of $\mathrm{F}(\mathrm{x})$ in the $\mathrm{i}$ th subproblem, $\beta$ is the preset penalty parameter, and $\mathrm{d}_{2}^{\mathrm{i}}$ denotes the distance between $\mathrm{F}(\mathrm{x})$ and direction line in the $\mathrm{i}$ th subproblem. In comparison with the Tchebycheff approach, the PBI approach has two advantages: (1) With the same weight vectors in more than two objective problem, the optimal solutions by PBI has more uniform distribution than those obtained by Tchebycheff approach; (2) If optimal solution $\mathrm{x}$ dominates another solution $\mathrm{y}$, it is possible that $\mathrm{g}^{\mathrm{pbi}}\left(\mathrm{x} \mid \lambda^{\mathrm{i}}, \mathrm{z}^{*}\right)=\mathrm{g}^{\mathrm{pbi}}\left(\mathrm{y} \mid \lambda^{\mathrm{i}}, \mathrm{z}^{*}\right)$ when $\mathrm{x}$ dominates $\mathrm{y}$, the attribute is however rare for other boundary intersection aggregation functions, it can properly improve the diversity of Pareto optimal front [15].

Since the feasible domain is divided into several levels according to different uncertainty budgets with probability 
distribution, it searches optimal solutions as well as considers the probability of obtained scheme. The PBI method can be extended to solve stochastic optimization problem with probabilistic feasible region, it exists optimal solution in each feasible region. With consideration of the probabilistic distribution, PBI for probabilistic optimization problem can be expressed as:

$$
\left\{\begin{array}{l}
\min \mathrm{g}^{\mathrm{pbi}}\left(\mathrm{x} \mid \lambda^{\mathrm{i}}, \mathrm{z}^{*}\right)=\sum_{\mathrm{s}=1}^{\mathrm{s}} \operatorname{Pr}\left(\Delta_{\mathrm{t}}^{(\mathrm{s})}\right)\left(\mathrm{d}_{1}^{\mathrm{i}(\mathrm{s})}+\beta \mathrm{d}_{2}^{\mathrm{i}(\mathrm{s})}\right)+\mu\|\Theta\|_{2} \\
\mathrm{~d}_{1}^{\mathrm{i}(\mathrm{s})}=\left(\mathrm{F}\left(\mathrm{x}^{(\mathrm{s})}\right)-\mathrm{z}^{*}\right)^{\mathrm{T}} \lambda^{\mathrm{i}} /\left\|\lambda^{\mathrm{i}}\right\| \\
\mathrm{d}_{2}^{\mathrm{i}(\mathrm{s})}=\left\|\mathrm{F}\left(\mathrm{x}^{(\mathrm{s})}\right)-\mathrm{z}^{*}-\left(\mathrm{d}_{1}^{\mathrm{i}(\mathrm{s})} /\left\|\lambda^{\mathrm{i}}\right\|\right) \lambda^{\mathrm{i}}\right\| \\
\mathrm{x}^{(\mathrm{s})} \in \Omega, \mathrm{s}=1,2, \ldots, \mathrm{S}
\end{array}\right.
$$

where $\mathrm{s}$ is scenario index, and $\mathrm{S}$ is the total scenario number, $\Delta_{t}^{(s)}$ is the uncertainty budget of scenario $s$ at $t$ th time period, $\mathrm{d}_{1}^{\mathrm{i}(\mathrm{s})}$ denotes the distance between projection point and $z^{*}$, and $d_{2}^{i(s)}$ denotes the distance between initial point and projection point, $\mu$ is discount factor, it can be considered as a regularization parameter, which mainly controls the scale of scenario vector. $\mathrm{x}^{(\mathrm{s})}$ is simulated value of scenario s. Since scenarios can increase computational complexity, the number of scenarios cannot exceed certain degree, regularization operator $\|\Theta\|_{2}$ can be employed to control the scale of scenarios, and where $\Theta=\left[\operatorname{Pr}\left(\Delta_{\mathrm{t}}^{(1)}\right), \operatorname{Pr}\left(\Delta_{\mathrm{t}}^{(2)}\right), \ldots, \operatorname{Pr}\left(\Delta_{\mathrm{t}}^{(\mathrm{S})}\right)\right]^{\mathrm{T}}$.

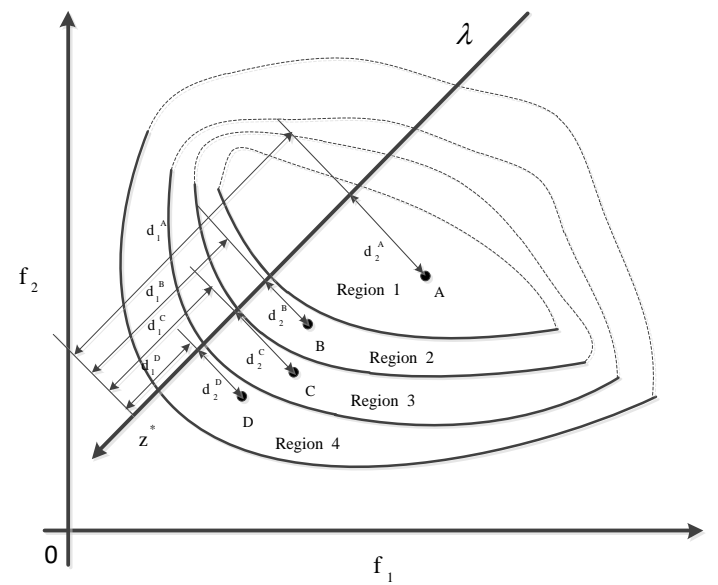

Fig.2 The probabilistic PBI method with different scenarios

In probabilistic PBI method, those generated scenarios are scattered into the $f_{1}-f_{2}$ space, which has been classified into different regions. Each region has several scenarios with certain probabilistic characteristics, to search the optimal solution of the stochastic problem, expected value replaces the objective in formula (17), as is shown in Fig.2. The probabilistic characteristics can be obtained with PDF of wind power and PV power generation, which can be expressed with uncertainty budget. With above MOEA/D framework, this paper utilizes DE (Differential evolution) to solve above scalar subproblems with different weights due to its simple yet powerful search ability in comparison to other heuristic optimization algorithms, DE procedure is taken with mutation operator of $\mathrm{DE} / \mathrm{rand} / 1 / \mathrm{bin}$, which is generally demonstrated as:

$$
\begin{aligned}
& \mathrm{V}_{\mathrm{r}, \mathrm{G}+1}=\mathrm{X}_{\mathrm{r}, \mathrm{G}}+\gamma *\left[\left(\mathrm{X}_{\mathrm{r} 1, \mathrm{G}}-\mathrm{X}_{\mathrm{r} 2, \mathrm{G}}\right)+\left(\mathrm{X}_{\mathrm{r} 3, \mathrm{G}}-\mathrm{X}_{\mathrm{r} 4, \mathrm{G}}\right)\right], \\
& \mathrm{r} 1 \neq \mathrm{r} 2 \neq \mathrm{r} 3 \neq \mathrm{r} 4 \neq \mathrm{r}
\end{aligned}
$$

where $\mathrm{V}_{\mathrm{r}, \mathrm{G}}$ is the parameter vector for $\mathrm{G}+1$-th generation, $\gamma$ is the mutation parameter, which is range in $[0,2]$. $\mathrm{X}_{\mathrm{r} 1, \mathrm{G}}, \mathrm{X}_{\mathrm{r} 2, \mathrm{G}}, \mathrm{X}_{\mathrm{r} 3, \mathrm{G}}, \mathrm{X}_{\mathrm{r} 4, \mathrm{G}}$ are randomly selected individual in the archive set, which mainly stores the non-dominated solutions in each generation. For improving the search ability of DE, gradient decent based DE procedure is taken as it is shown in literature [32]. The improved mutation operator can be improved as follows:

$$
\begin{aligned}
& \mathrm{X}_{\mathrm{G}+1}^{\mathrm{j}}=\mathrm{X}_{\mathrm{r}, \mathrm{G}}^{\mathrm{j}}+\gamma_{1}^{\mathrm{j}}\left(\mathrm{X}_{\mathrm{r} 1, \mathrm{G}}-\mathrm{X}_{\mathrm{r} 2, \mathrm{G}}\right)+\gamma_{2}^{\mathrm{j}}\left(\mathrm{X}_{\mathrm{r} 3, \mathrm{G}}-\mathrm{X}_{\mathrm{r} 4, \mathrm{G}}\right) \\
& \mathrm{r} 1 \neq \mathrm{r} 2 \neq \mathrm{r} 3 \neq \mathrm{r} 4 \neq \mathrm{r}
\end{aligned}
$$

$$
\left\{\begin{array}{l}
\gamma_{1}^{\mathrm{j}}=\frac{-\eta_{\mathrm{G}} \lambda_{1} * \operatorname{sgn}\left(\mathrm{f}_{1}\left(\mathrm{X}_{\mathrm{r} 1, \mathrm{G}}\right)-\mathrm{f}_{1}\left(\mathrm{X}_{\mathrm{r} 2, \mathrm{G}}\right)\right)}{\left(\mathrm{X}_{\mathrm{r} 1, \mathrm{G}}^{\mathrm{j}}-\mathrm{X}_{\mathrm{r} 2, \mathrm{G}}^{\mathrm{j}}\right)^{2} \sqrt{\sum_{\mathrm{j}=1}^{\mathrm{n}} \frac{1}{\left(\mathrm{X}_{\mathrm{r} 1, \mathrm{G}}^{\mathrm{j}}-\mathrm{X}_{\mathrm{r} 2, \mathrm{G}}^{\mathrm{j}}\right)^{2}}}} \\
\gamma_{2}^{\mathrm{j}}=\frac{-\eta_{\mathrm{G}} \lambda_{2} * \operatorname{sgn}\left(\mathrm{f}_{2}\left(\mathrm{X}_{\mathrm{r} 3, \mathrm{G}}\right)-\mathrm{f}_{2}\left(\mathrm{X}_{\mathrm{r} 4, \mathrm{G}}\right)\right)}{\left(\mathrm{X}_{\mathrm{r} 3, \mathrm{G}}^{\mathrm{j}}-\mathrm{X}_{\mathrm{r} 4, \mathrm{G}}^{\mathrm{j}}\right)^{2} \sqrt{\sum_{\mathrm{j}=1}^{\mathrm{n}} \frac{1}{\left(\mathrm{X}_{\mathrm{r} 3, \mathrm{G}}^{\mathrm{j}}-\mathrm{X}_{\mathrm{r} 4, \mathrm{G}}^{\mathrm{j}}\right)^{2}}}} \\
\eta_{\mathrm{G}}=\eta_{0}\left[\left(\mathrm{~g}_{\max }-\mathrm{G}+1\right) / \mathrm{g}_{\max }\right]^{\mathrm{p}}
\end{array}\right.
$$

where $\eta_{\mathrm{G}}$ is the scaling parameter at the $\mathrm{G}$ th generation, and $\eta_{0}$ is the initial scaling parameter, $\mathrm{G}_{\max }$ is the maximum generation, $\lambda_{1}$ is weighted parameter in interval $[0,1], \gamma_{1}^{\mathrm{j}}, \gamma_{2}^{\mathrm{j}}$ are the mutation parameters. The gradient decent method searches the optimal solution along the shortest direction, which speeds up the search ability of DE. The weights of those subsystems can also be properly set, which can be seen in literature [33].

\section{THE FUZZY DECISION-MAKING METHOD FOR THE PROBABILISTIC OPTIMAL PROBLEM}

\section{A. Fuzzy decision-making approach}

Due to the uncertainty of intermittent power introduced into the hybrid energy system, each optimal scheme from non-dominated solutions contains different risk levels after multi-objective optimization. Hence, the best scheme should be a tradeoff among different objectives, and at the same time it also has the lowest risk level. Once, those Pareto optimal solutions are obtained with above optimization method, it can be assumed that probability of optimal solutions $\mathrm{X}^{*}=\left[\mathrm{X}_{1}^{*}, \mathrm{X}_{2}^{*}, \ldots, \mathrm{X}_{\mathrm{N}_{\mathrm{A}}}^{*}\right]$ can be expressed as follows: 


$$
\operatorname{Prob}\left(X_{i}^{*}\right)=\prod_{s=1}^{N_{s}} \operatorname{Pr}^{(i)}(s), \quad\left(i=1,2, \ldots, N_{A}\right)
$$

where $\operatorname{Pr}^{(i)}(s)$ is the probability of the $s$ th scenario in the $i$ th optimal solution. With consideration of stochastic problem and multiple objectives, some remarks can be defined as follows:

Remark 1: Suppose the reference uncertainty budget at $t$ th time period $\Delta_{\mathrm{t}}^{(\alpha)^{*}}$, the uncertainty deviation between reference uncertainty budget and the resultant uncertainty budget can be defined as the uncertainty metric.

$$
\operatorname{Unc}(\eta)=\left|\sum_{\mathrm{t}=1}^{\mathrm{T}} \Delta_{\mathrm{t}}^{(\eta)}-\sum_{\mathrm{t}=1}^{\mathrm{T}} \Delta_{\mathrm{t}}^{(\eta)^{*}}\right|
$$

where $\Delta_{\mathrm{t}}^{(\alpha)}$ is the $\Delta_{\mathrm{t}}$ of the $\eta$ th situation, $\eta$ is the number of Pareto optimal set. When uncertainty metric is large, it means that those uncertainty budget settings are not close to real-world application. Hence, the best solution should have less deviation to ensure the practicality. Combined with the evaluation value, the decision-making method can be used to choose the best optimal solution for applications. Firstly, best uncertainty set $\eta^{*}$ should be selected with the smallest uncertainty deviation, it can be obtained by:

$$
\eta^{*}=\underset{\eta \in \Omega_{\eta}}{\arg \min }\left|\sum_{\mathrm{t}=1}^{\mathrm{T}} \Delta_{\mathrm{t}}^{(\eta)}-\sum_{\mathrm{t}=1}^{\mathrm{T}} \Delta_{\mathrm{t}}^{(\eta)^{*}}\right|
$$

where $\Omega_{\eta}$ is the index set of uncertainty set. Once the optimal uncertainty set $\Delta_{\mathrm{t}}^{\left(\eta^{*}\right)}$ is obtained, the best Pareto optimal front can be selected with above uncertainty deviation.

Remark 2: To properly evaluate each optimal solution in the archive set, the $f_{1}-f_{2}$ space is firstly divided into several small grids, and width on $f_{1}$ direction of each box is $\delta_{1}=\left(\mathrm{f}_{1, \text { max }}-\mathrm{f}_{1, \text { min }}\right) / \mathrm{N}_{\mathrm{A}}$, and the length on $\mathrm{f}_{2}$ direction of each box is $\delta_{2}=\left(\mathrm{f}_{2, \max }-\mathrm{f}_{2 \text {,min }}\right) / \mathrm{N}_{\mathrm{A}}$. For two given optimal solutions $X_{i}^{*}, X_{j}^{*}(j \neq i)$, there exists an evaluation index $\operatorname{Eval}_{\mathrm{ij}}(\mathrm{m})(\mathrm{m}=1,2, \ldots, \mathrm{M})$ and $\mathrm{K}_{1}, \mathrm{~K}_{2} \in \mathrm{Z}^{+}$, which represent the location of objective value in $\mathrm{f} 1-\mathrm{f} 2$ coordinate axis. Here $\mathrm{M}=2$ for simplicity, for $\mathrm{m}=1$, if $\mathrm{K}_{1} \delta_{1} \leq\left|\mathrm{f}_{1}\left(\mathrm{X}_{\mathrm{i}}^{*}\right)-\mathrm{f}_{1}\left(\mathrm{X}_{\mathrm{j}}^{*}\right)\right| \leq\left(\mathrm{K}_{1}+1\right) \delta_{1}, \operatorname{Eval}_{\mathrm{ij}}(\mathrm{m})=\mathrm{K}_{1} \delta_{1}$; For $\mathrm{m}=2$, if $\mathrm{K}_{2} \delta_{2} \leq\left|\mathrm{f}_{2}\left(\mathrm{X}_{\mathrm{i}}^{*}\right)-\mathrm{f}_{2}\left(\mathrm{X}_{\mathrm{j}}^{*}\right)\right| \leq\left(\mathrm{K}_{2}+1\right) \delta_{2}$, then $\operatorname{Eval}_{\mathrm{ij}}(\mathrm{m})=\mathrm{K}_{2} \delta_{2}$. The evaluation value between $\mathrm{X}_{\mathrm{i}}^{*}$ and $\mathrm{X}_{\mathrm{j}}^{*}$ can be expressed as:

$$
\operatorname{Eval}_{\mathrm{ij}}=\sum_{\mathrm{m}=1}^{\mathrm{M}} \operatorname{Eval}_{\mathrm{ij}}(\mathrm{m})
$$

With consideration of the archive set, the evaluation value of $\mathrm{X}_{\mathrm{i}}^{*}$ can be obtained as follows:

$$
\operatorname{Eval}_{\mathrm{i}}=\sum_{\mathrm{j}=1, \mathrm{j} \neq \mathrm{i}}^{\mathrm{N}_{\mathrm{A}}} \mathrm{Eval}_{\mathrm{ij}}
$$

The optimal index can be obtained:

$$
i^{*}=\underset{i=1,2 \ldots, N_{\mathrm{A}}}{\arg \max }\left(\operatorname{Eval}_{\mathrm{i}}\right)
$$

\section{B. Probabilistic risk evalution}

On the other side, the uncertainty budget $\Delta_{t}$ also should be properly set, it mainly relates to the reliability of the hybrid energy system. The spinning reserve and system load balance can ensure the reliability of power system, since BESS can provide complimentary power, BESS can also be considered to assure the safety or reliability issue. Combine formulation (7) and (15) together can obtain:

$$
\begin{aligned}
& \sum_{\mathrm{i} \in \mathrm{N}_{\mathrm{c}}} \mathrm{P}_{\text {ci max }}+\sum_{1 \in \mathrm{N}_{\mathrm{b}}} \mathrm{P}_{1, \max }^{\mathrm{dis}}+\sum_{\mathrm{j} \in \mathrm{N}_{\mathrm{w}}} \mathrm{P}_{\mathrm{wjt}}+\sum_{\mathrm{k} \in \mathrm{N}_{\mathrm{p}}} \mathrm{P}_{\mathrm{pkt}} \geq \\
& \mathrm{P}_{\mathrm{D}, \mathrm{t}}+\sum_{\mathrm{j} \in \mathrm{N}_{\mathrm{I}}} \gamma_{\mathrm{Ijt}}\left(\tilde{\mathrm{P}}_{\mathrm{Ijt}}^{\mathrm{max}}-\tilde{\mathrm{P}}_{\mathrm{Ijt}}^{\mathrm{min}}\right)
\end{aligned}
$$

According to literature [28], the probability of formula (28) satisfy:

$$
\begin{aligned}
& \operatorname{Pro}\left\{\sum_{\mathrm{i} \in \mathrm{N}_{\mathrm{c}}} \mathrm{P}_{\mathrm{cimax}}+\sum_{1 \in \mathrm{N}_{\mathrm{b}}} \mathrm{P}_{1, \max }^{\mathrm{dis}}+\sum_{\mathrm{j} \in \mathrm{N}_{\mathrm{w}}} \mathrm{P}_{\mathrm{wjt}}+\sum_{\mathrm{k} \in \mathrm{N}_{\mathrm{p}}} \mathrm{P}_{\mathrm{pkt}}\right. \\
& \left.<\mathrm{P}_{\mathrm{D}, \mathrm{t}}+\sum_{\mathrm{j} \in \mathrm{N}_{\mathrm{I}}} \gamma_{\mathrm{Ijt}}\left(\tilde{\mathrm{P}}_{\mathrm{ljt}}^{\mathrm{max}}-\tilde{\mathrm{P}}_{\mathrm{Ijt}}^{\min }\right)\right\} \leq \operatorname{Pro}\left(\sum_{\mathrm{j} \in \mathrm{N}_{\mathrm{I}}} \mathrm{W}_{\mathrm{Ijt}} \gamma_{\mathrm{Ijt}} \geq \Delta_{\mathrm{t}}\right)
\end{aligned}
$$

Where

$$
\mathrm{W}_{\mathrm{Ijt}}=\left\{\begin{array}{l}
1, \mathrm{j} \in \mathrm{R}_{\mathrm{t}}^{\#} \\
\frac{\tilde{\mathrm{P}}_{\mathrm{Ijt}}^{\max }}{\min \left\{\tilde{\mathrm{P}}_{\mathrm{Igt}}^{\max }\right\}}, \mathrm{j} \in \mathrm{N}_{\mathrm{I}} \backslash \mathrm{R}_{\mathrm{t}}^{\#}, \text { where } \mathrm{g} \in \mathrm{R}_{\mathrm{r}}^{\#} \cup\{\mathrm{m}\}
\end{array}\right.
$$

$\mathrm{R}_{\mathrm{t}}^{\#}$ is the set of intermittent power with extreme output, Suppose that those are independent random variables and follow distribution in formula (11) and (12), with Markov inequality it can obtain:

$$
\operatorname{Pro}\left(\sum_{\mathrm{j} \in \mathrm{N}_{\mathrm{I}}} \mathrm{w}_{\mathrm{Ijt}} \gamma_{\mathrm{Ijt}} \geq \Delta_{\mathrm{t}}\right) \leq \frac{\mathrm{E}\left(\sum_{\mathrm{j} \in \mathrm{N}_{\mathrm{I}}} \mathrm{w}_{\mathrm{Ijt}} \gamma_{\mathrm{Ijt}}\right)}{\Delta_{\mathrm{t}}}
$$

For simplicity, denote two random variables $\mathrm{x}=\sum_{\mathrm{j} \in \mathrm{N}_{\mathrm{w}}} \mathrm{w}_{\mathrm{Ijt}} \gamma_{\mathrm{Ijt}}, \mathrm{y}=\sum_{\mathrm{j} \in \mathrm{N}_{\mathrm{p}}} \mathrm{w}_{\mathrm{Ijt}} \gamma_{\mathrm{Ijt}}$, then it can be deduced as follows: 

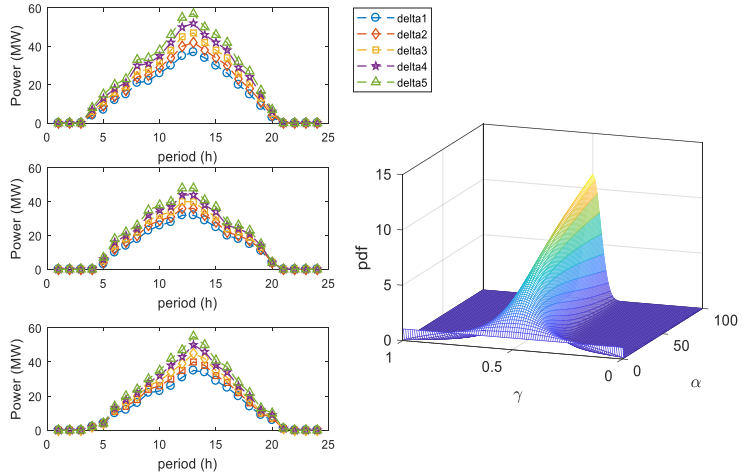

Fig.3 (a) PV uncertainty with five levels and its PDF
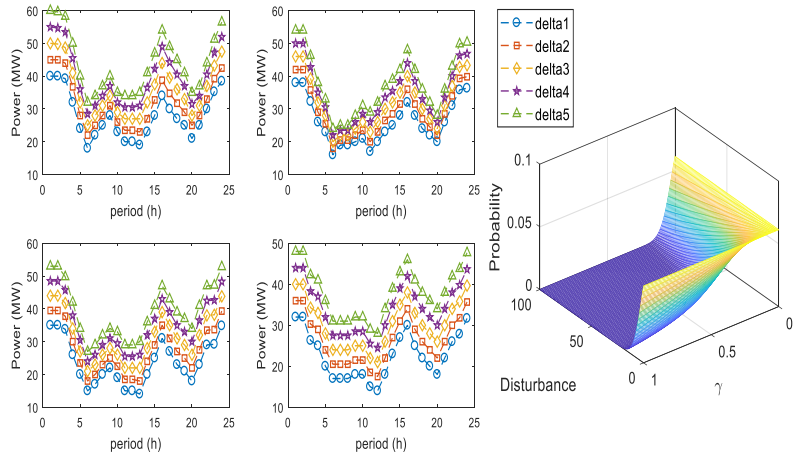

Fig.3 (b) Wind power uncertainty with five levels and its PDF
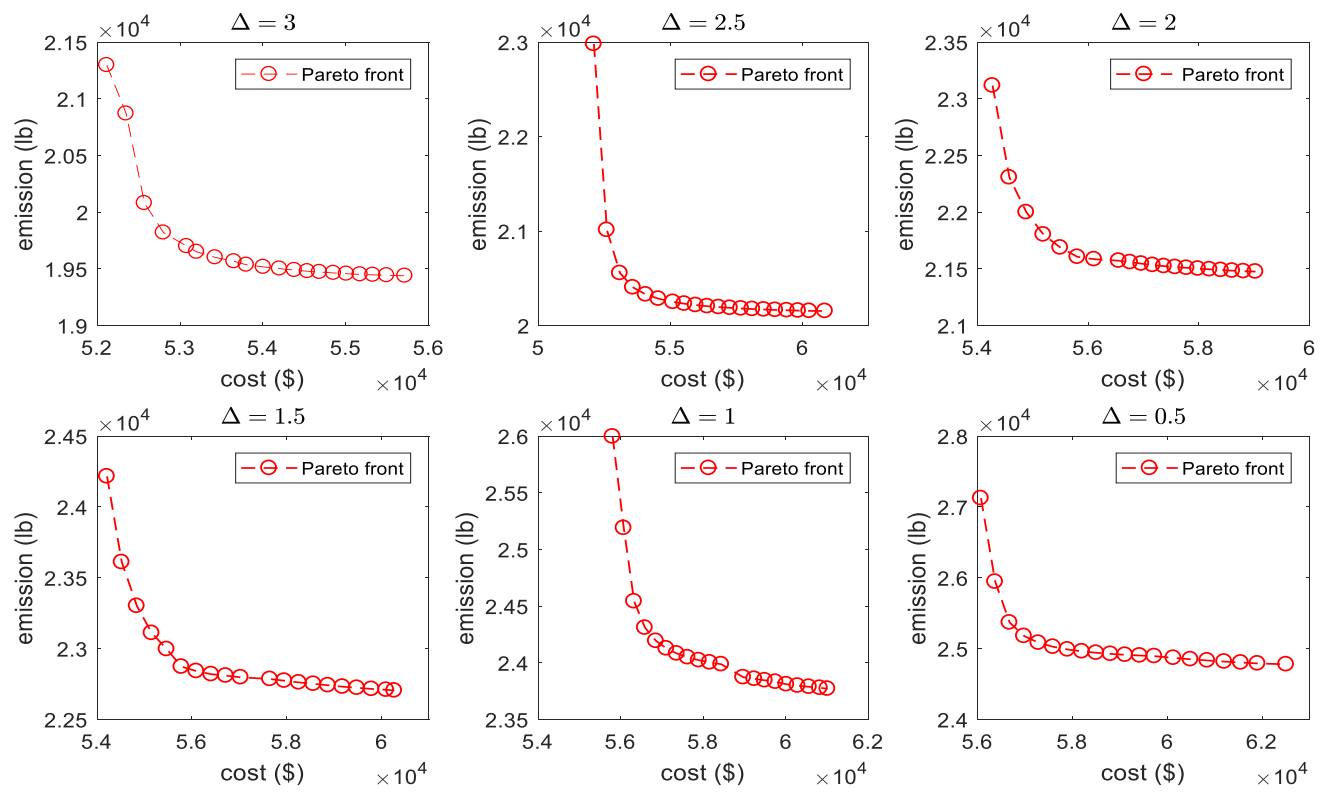

Fig.4 Pareto fronts under different uncertainty budgets

$\operatorname{Pro}\left(\sum_{\mathrm{j} \in \mathrm{N}_{\mathrm{I}}} \mathrm{w}_{\mathrm{Ijt}} \gamma_{\mathrm{Ijt}} \geq \Delta_{\mathrm{t}}\right) \leq\left(\mathrm{N}_{\mathrm{w}}-\Delta_{\mathrm{t}}\right) \mathrm{e}^{-\left(\mathrm{v}_{\mathrm{in}} / \mathrm{c}\right)^{\mathrm{k}}}+\mathrm{e}^{-\Delta_{\mathrm{t}}^{2} / 2\left(\mathrm{~N}_{\mathrm{p}}+\mathrm{N}_{\mathrm{w}}\right)}$

Then the probability of constraint limit (28) satisfies:

$$
\begin{aligned}
& \operatorname{Pro}\left\{\sum_{\mathrm{i} \in \mathrm{N}_{\mathrm{c}}} \mathrm{P}_{\mathrm{cimax}}+\sum_{1 \in \mathrm{N}_{\mathrm{b}}} \mathrm{P}_{1, \text { max }}^{\mathrm{dis}}+\sum_{\mathrm{j} \in \mathrm{N}_{\mathrm{w}}} \mathrm{P}_{\mathrm{wjt}}+\sum_{\mathrm{k} \in \mathrm{N}_{\mathrm{p}}} \mathrm{P}_{\mathrm{pkt}}\right. \\
& \left.<\mathrm{P}_{\mathrm{D}, \mathrm{t}}+\sum_{\mathrm{j} \in \mathrm{N}_{\mathrm{t}}} \gamma_{\mathrm{Ijt}}\left(\tilde{\mathrm{P}}_{\mathrm{Ijt}}^{\max }-\tilde{\mathrm{P}}_{\mathrm{Ijt}}^{\min }\right)\right\} \\
& \leq\left(\mathrm{N}_{\mathrm{w}}-\Delta_{\mathrm{t}}\right) \mathrm{e}^{-\left(\mathrm{v}_{\mathrm{in}} / \mathrm{c}^{\mathrm{k}}\right.}+\mathrm{e}^{-\Delta_{\mathrm{t}}^{2} / 2\left(\mathrm{~N}_{\mathrm{p}}+\mathrm{N}_{\mathrm{w}}\right)}
\end{aligned}
$$

Suppose that the probability of formula (28) should be controlled at least with probability of $1-\delta$, and then the appropriate upper bound of uncertainty budget can be calculated:

$$
\kappa \geq \Delta_{\mathrm{t}} \geq 0
$$

Generally, $\Delta_{\mathrm{t}}$ can be set as large as possible if possible risk has been properly avoided, it also means that $\kappa$ is the permitted maximum value of uncertainty budget, and the optimal uncertainty set $\Delta_{\mathrm{t}}^{\left(\eta^{*}\right)}$ can be deduced, which also means that potential risk can be prevented if formula (34) is properly satisfied. Since it is difficult to deduce the analytical solution, $\kappa$ value is deduced in simulation.

\section{Simulations}

The simulation can be implemented with following procedures: (1) Making analysis on the probabilistic characteristics of wind and PV power generation; (2) With consideration of potential risk, it deduces proper uncertainty budget; (3) Optimizing hybrid energy system with MOEAD-GDDE approach; (4) Decision-making on those obtained optimal solutions, and produce best optimal scheme for hybrid energy system operation.

\section{A. Parameters settings and basic data}

The hybrid energy system consists of wind power, solar power, thermal power and energy storage, it includes five 
Table.1 The comparison with other alternatives under different uncertainties

\begin{tabular}{ccccc}
\hline Algorithms & Uncertainty & Cost $\mathbf{(})$ & Emission $(\mathbf{l b})$ & Time (s) \\
\hline \multirow{3}{*}{ NSGA-II } & $\Delta=3$ & 54211 & 19823 & 660 \\
\cline { 2 - 5 } & $\Delta=2$ & 57229 & 22619 & 581 \\
\cline { 2 - 5 } MOEA/D-TPN & $\Delta=1$ & 59541 & 24766 & 543 \\
\cline { 2 - 5 } & $\Delta=3$ & 54358 & 19818 & 632 \\
\cline { 2 - 5 } MOPSO & $\Delta=2$ & 57543 & 22153 & 558 \\
\cline { 2 - 5 } & $\Delta=1$ & 59712 & 24899 & 511 \\
\hline \multirow{3}{*}{ MOHDE } & $\Delta=3$ & 54386 & 20518 & 610 \\
& $\Delta=2$ & 57871 & 22763 & 532 \\
\hline \multirow{3}{*}{ MOEA/D-GDDE } & $\Delta=1$ & 60012 & 25314 & 598 \\
\cline { 2 - 5 } & $\Delta=3$ & 54206 & 19520 & 512 \\
\cline { 2 - 5 } & $\Delta=2$ & 56488 & 21590 & 677 \\
\hline & $\Delta=1$ & 59012 & 24007 & 553 \\
\hline
\end{tabular}

thermal units, 2 energy storages, four wind farms and three photovoltaic fields, the data resource can be found in [30]. The uncertainty domain of intermittent power output is divided into five levels, instead of setting different uncertainty budgets at different periods, uncertainty budget at each time period can be considered as the same value. The PDF within uncertainty domain is illustrated in Fig.3 (a) and Fig.3 (b) respective. PV generators mainly work from 8:00 to 20:00 and its output achieves the maximum value at noon, while wind power fluctuates frequently, it mainly achieves the maximum output at 00:00-02:00 and 15:00-17:00. PV power follows Beta distribution (after normalization) and wind power follows density distribution of formula (11), where parameters are set as $\alpha=\beta=2, \mathrm{c}=\mathrm{v}_{\text {in }}=3 \mathrm{~m} / \mathrm{s}, \mathrm{v}_{\text {rate }}=13 \mathrm{~m} / \mathrm{s}, \mathrm{P}_{\mathrm{rate}}=60 \mathrm{MW}$. Since the number of wind farms and PV cannot exceed 8 , it satisfies $\left|\frac{\Delta_{t}^{2}}{2\left(N_{w}+N_{p}\right)}\right|<1$, therefore the second term of formula (33) can be expressed by the first four terms of the Taylor series expansion, then formula (33) can be rewritten as:

$$
\begin{aligned}
& \operatorname{Pro}\left\{\sum_{\mathrm{i} \in \mathrm{N}_{\mathrm{c}}} \mathrm{P}_{\mathrm{cimax}}+\sum_{\mathrm{l} \in \mathrm{N}_{\mathrm{b}}} \mathrm{P}_{\mathrm{l}, \max }^{\mathrm{dis}}+\sum_{\mathrm{j} \in \mathrm{N}_{\mathrm{w}}} \mathrm{P}_{\mathrm{wjt}}+\sum_{\mathrm{k} \in \mathrm{N}_{\mathrm{p}}} \mathrm{P}_{\mathrm{pkt}}\right. \\
& \left.<\mathrm{P}_{\mathrm{D}, \mathrm{t}}+\sum_{\mathrm{j} \in \mathrm{N}_{\mathrm{l}}} \gamma_{\mathrm{ljt}}\left(\tilde{\mathrm{P}}_{\mathrm{Ijt}}^{\max }-\tilde{\mathrm{P}}_{\mathrm{Ijt}}^{\min }\right)\right\} \\
& \leq 1+\left(\mathrm{N}_{\mathrm{w}}-\Delta_{\mathrm{t}}\right) \mathrm{e}^{-\left(\mathrm{v}_{\mathrm{in}} / \mathrm{c}\right)^{\mathrm{k}}}-\frac{5}{16} \frac{\Delta_{\mathrm{t}}^{2}}{\mathrm{~N}_{\mathrm{p}}+\mathrm{N}_{\mathrm{w}}}
\end{aligned}
$$

The parameter $\kappa$ can also be calculated as:

$$
\begin{aligned}
\kappa= & \sqrt{\frac{64}{25} \mathrm{~N}_{\mathrm{I}}^{2} \mathrm{e}^{-2\left(v_{\text {in }} / c\right) \mathrm{k}}+\frac{64}{25} \mathrm{~N}_{\mathrm{I}}\left(1+\mathrm{N}_{\mathrm{w}} \mathrm{e}^{-\left(\mathrm{v}_{\text {in }} / \mathrm{c}\right)^{\mathrm{k}}}-\delta\right)} \\
& -\frac{8}{5} \mathrm{~N}_{\mathrm{I}} \mathrm{e}^{-\left(\mathrm{v}_{\text {in }} / \mathrm{c}\right)^{\mathrm{k}}}
\end{aligned}
$$

The parameters for population evolution can be set as follows: population size is set as 200 , maximum generation size is 1000 , the number of Pareto optimal solutions is 20 , the initial scaling parameter $\eta_{0}$ is set to 0.8 , and the number of scenarios is 50, which is deduced as $[34,35]$ :

$$
\sum_{\mathrm{i}=0}^{\mathrm{k}}\left(\begin{array}{l}
\mathrm{N} \\
\mathrm{i}
\end{array}\right) \varepsilon^{\mathrm{i}}(1-\varepsilon)^{\mathrm{N}-\mathrm{i}} \leq \beta
$$

where $\varepsilon \in(0,1)$ is violation parameter (here it can be considered as scenario probability), $\beta$ is confidence parameter, it is generally $10^{-6}$.

\section{B. Results and analysis}

50 scenarios are generated to simulate the stochastic process, the stochastic model of hybrid energy system can be created, combined with MOEA/D approach, 20 Pareto optimal schemes can be calculated with each uncertainty budget, which have been shown in Fig.4. Economic cost, emission issue and computational time are taken as metrics. In comparison to other representative MOEAs including NSGA-II [3], MOEA/D-TPN [36], MOPSO [37], and MOHDE [7], the proposed MOEA/D-GDDE can obtain both lower cost and emission at certain time, which are listed in Table.1. It can be seen that the proposed MOEA/D-GDDE is superior to other alternatives on cost and emission objectives, since it integrates probabilistic analysis into optimization, computational time is merely better than a few of them. Here, three typical uncertainty budgets provide different uncertainty domain of intermittent power generations, it is also found that the results with larger uncertainty budget have lower/better economic cost and emission, it can be explained that large uncertainty budget provides large feasible domain for optimization method, and it further promotes search scale and find the global optima. Since the scheduling process of each time period can be quite similar for most of the time, uncertainty budget can be set as the same value. 


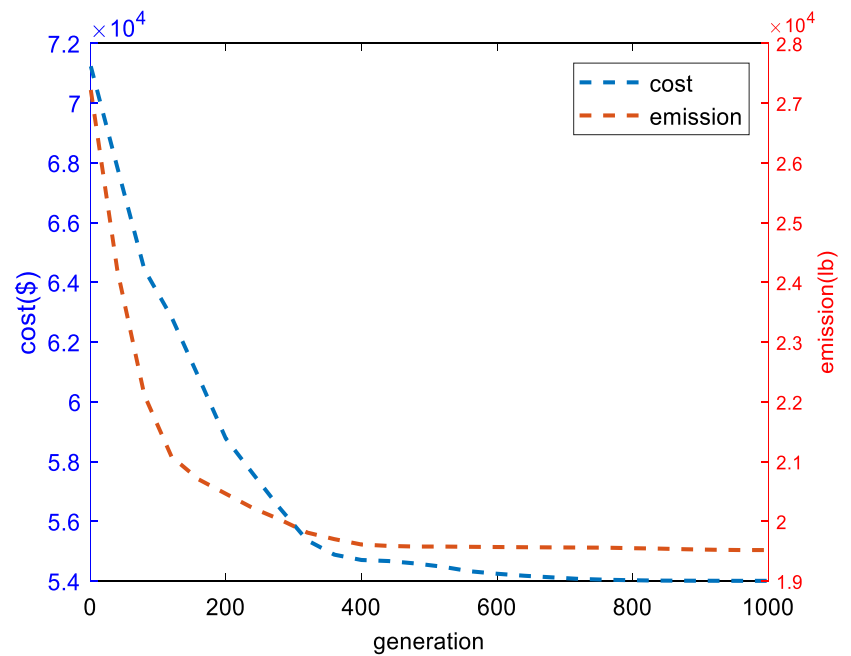

Fig.5(a) convergence of cost and emission with $\Delta=3$

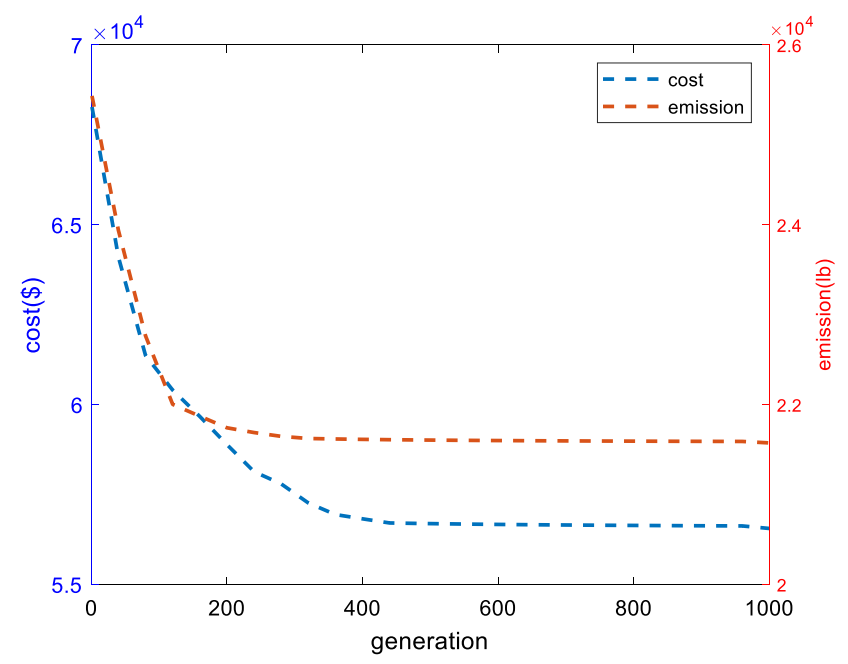

Fig.5(b) convergence of cost and emission with $\Delta=2$

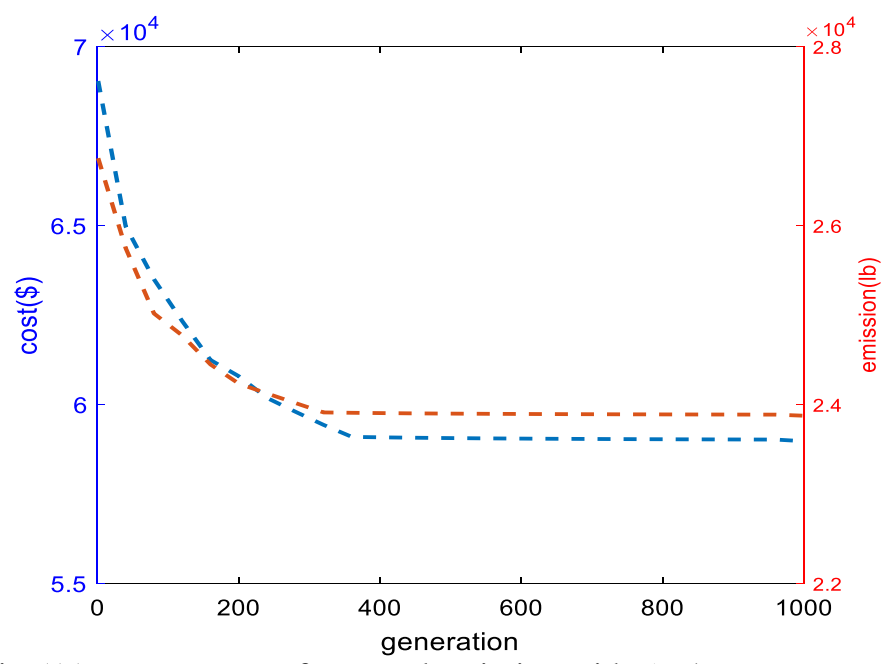

Fig.5(c) convergence of cost and emission with $\Delta=1$

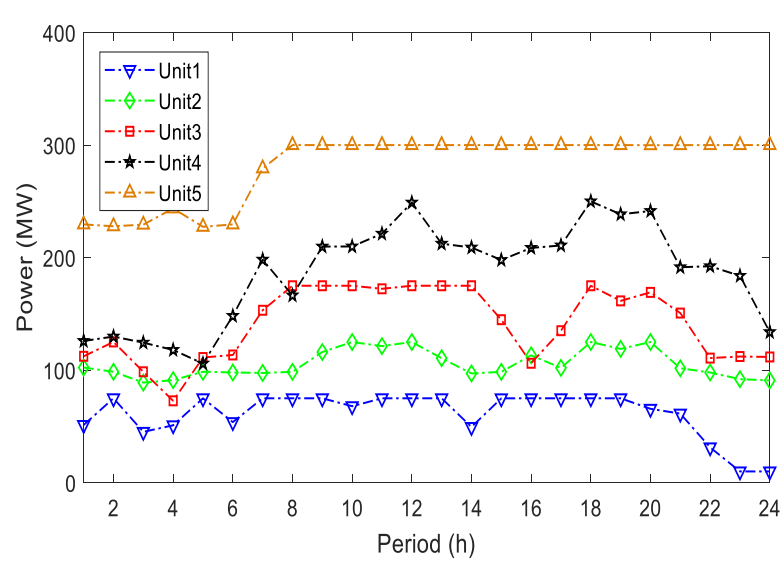

Fig.6 Thermal output process with $\Delta=3$

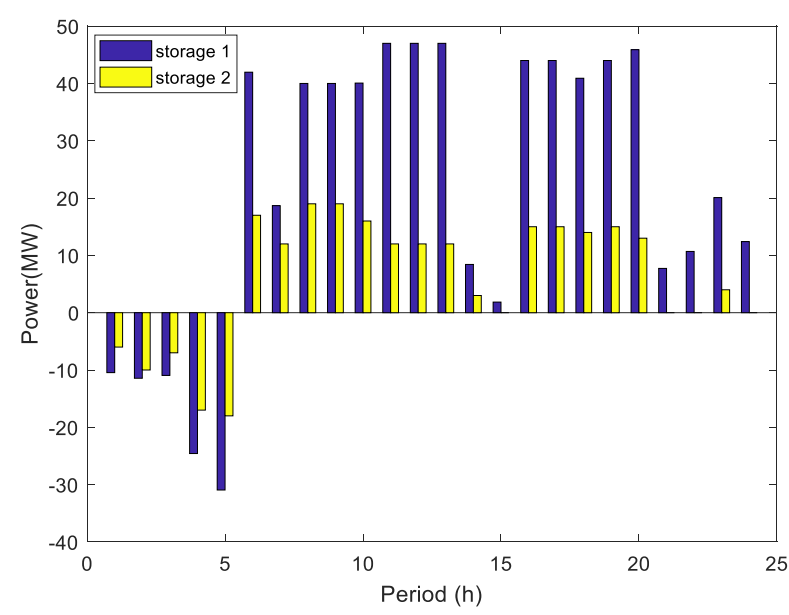

Fig.7 Storage process of BES with $\Delta=3$

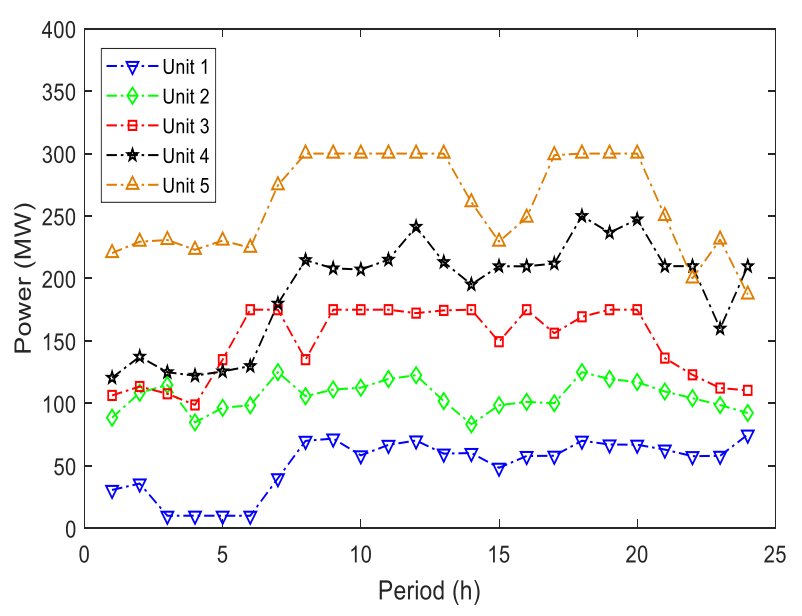

Fig.8 Thermal output process with $\Delta=2$ 
Table.2 The optimal adjustable parameter $\gamma_{\mathrm{Ijt}}$ under different uncertainty budgets

\begin{tabular}{ccccc}
\hline Periods & $\Delta=3$ & $\Delta=2$ & $\Delta=1$ \\
\hline $00: 00-00: 59$ & $\{0,0,0\},\{1,1,1,0\}$ & $\{0,0,0\},\{1,1,0,0\}$ & $\{0,0,0\},\{1,0,0,0\}$ \\
01:00-01:59 & $\{0,0,0\},\{1,1,1,0\}$ & $\{0,0,0\},\{1,1,0,0\}$ & $\{0,0,0\},\{1,0,0,0\}$ \\
02:00-02:59 & $\{0,0,0\},\{1,1,1,0\}$ & $\{0,0,0\},\{1 / 2,1 / 2,1 / 2,1 / 2\}$ & $\{0,0,0\},\{1 / 4,1 / 4,1 / 4,1 / 4\}$ \\
$03: 00-03: 59$ & $\{0,0,0\},\{3 / 4,3 / 4,3 / 4,3 / 4\}$ & $\{0,0,0\},\{1 / 2,1 / 2,1 / 2,1 / 2\}$ & $\{0,0,0\},\{1 / 4,1 / 4,1 / 4,1 / 4\}$ \\
$04: 00-04: 59$ & $\{0,0,0\},\{3 / 4,3 / 4,3 / 4,3 / 4\}$ & $\{0,0,0\},\{1 / 2,1 / 2,1 / 2,1 / 2\}$ & $\{0,0,0\},\{1 / 4,1 / 4,1 / 4,1 / 4\}$ \\
$05: 00-05: 59$ & $\{1 / 2,1 / 2,0\},\{1 / 2,1 / 2,1 / 2,1 / 2\}$ & $\{1 / 4,1 / 4,0\},\{1 / 2,1 / 2,1 / 4,1 / 4\}$ & $\{0,0,0\},\{1 / 4,1 / 4,1 / 4,1 / 4\}$ \\
$06: 00-06: 59$ & $\{1 / 2,1 / 2,0\},\{1 / 2,1 / 2,1 / 2,1 / 2\}$ & $\{1 / 4,1 / 4,0\},\{1 / 2,1 / 2,1 / 4,1 / 4\}$ & $\{0,0,0\},\{1 / 4,1 / 4,1 / 4,1 / 4\}$ \\
$07: 00-07: 59$ & $\{1 / 2,1 / 2,0\},\{1 / 2,1 / 2,1 / 2,1 / 2\}$ & $\{1 / 4,1 / 4,0\},\{1 / 2,1 / 2,1 / 4,1 / 4\}$ & $\{0,0,0\},\{1 / 4,1 / 4,1 / 4,1 / 4\}$ \\
$08: 00-08: 59$ & $\{1 / 4,1 / 4,1 / 4\},\{1 / 2,1 / 4,1 / 4,1 / 4\}$ & $\{1 / 4,1 / 4,1 / 4\},\{1 / 2,1 / 4,1 / 4,1 / 4\}$ & $\{1 / 4,0,0\},\{1 / 4,1 / 4,1 / 4,0\}$ \\
$09: 00-09: 59$ & $\{1 / 4,1 / 4,1 / 4\},\{1 / 2,1 / 4,1 / 4,1 / 4\}$ & $\{1 / 4,1 / 4,1 / 4\},\{1 / 2,1 / 4,1 / 4,1 / 4\}$ & $\{1 / 4,0,0\},\{1 / 4,1 / 4,1 / 4,0\}$ \\
$10: 00-10: 59$ & $\{1 / 2,1 / 2,1 / 2\},\{1 / 2,1 / 2,1 / 2,0\}$ & $\{1 / 4,1 / 4,1 / 4\},\{1 / 2,1 / 4,1 / 4,1 / 4\}$ & $\{1 / 4,1 / 4,0\},\{1 / 4,1 / 4,0,0\}$ \\
$11: 00-11: 59$ & $\{1 / 2,1 / 2,1 / 2\},\{1 / 2,1 / 2,1 / 2,0\}$ & $\{1 / 4,1 / 4,1 / 4\},\{1 / 2,1 / 4,1 / 4,1 / 4\}$ & $\{1 / 4,1 / 4,0\},\{1 / 4,1 / 4,0,0\}$ \\
$12: 00-12: 59$ & $\{3 / 4,3 / 4,0\}\{1 / 2,1 / 2,1 / 2,0\}$ & $\{1 / 2,1 / 4,1 / 4\},\{1 / 4,1 / 4,1 / 4,1 / 4\}$ & $\{1 / 2,1 / 4,0\},\{1 / 4,0,0,0\}$ \\
$13: 00-13: 59$ & $\{3 / 4,3 / 4,0\}\{1 / 2,1 / 2,1 / 2,0\}$ & $\{1 / 2,1 / 4,1 / 4\},\{1 / 4,1 / 4,1 / 4,1 / 4\}$ & $\{1 / 2,1 / 4,0\},\{1 / 4,0,0,0\}$ \\
$14: 00-14: 59$ & $\{1 / 2,1 / 2,1 / 2\},\{1 / 2,1 / 2,1 / 2,0\}$ & $\{1 / 2,1 / 4,1 / 4\},\{1 / 4,1 / 4,1 / 4,1 / 4\}$ & $\{1 / 2,1 / 4,0\},\{1 / 4,0,0,0\}$ \\
$15: 00: 15: 59$ & $\{1 / 2,1 / 2,1 / 2\},\{1 / 2,1 / 2,1 / 2,0\}$ & $\{1 / 2,1 / 4,1 / 4\},\{1 / 4,1 / 4,1 / 4,1 / 4\}$ & $\{1 / 2,1 / 4,0\},\{1 / 4,0,0,0\}$ \\
$16: 00-16: 59$ & $\{1 / 4,1 / 4,1 / 4\},\{1 / 2,1 / 4,1 / 4,1 / 4\}$ & $\{1 / 4,1 / 4,0\},\{1 / 2,1 / 2,1 / 4,1 / 4\}$ & $\{1 / 4,1 / 4,0\},\{1 / 4,1 / 4,0,0\}$ \\
$17: 00-17: 59$ & $\{1 / 4,1 / 4,1 / 4\},\{1 / 2,1 / 4,1 / 4,1 / 4\}$ & $\{1 / 4,1 / 4,0\},\{1 / 2,1 / 2,1 / 4,1 / 4\}$ & $\{1 / 4,1 / 4,0\},\{1 / 4,1 / 4,0,0\}$ \\
$18: 00-18: 59$ & $\{1 / 4,1 / 4,1 / 4\},\{1 / 2,1 / 4,1 / 4,1 / 4\}$ & $\{1 / 4,0,0\},\{1 / 2,1 / 2,1 / 2,1 / 4\}$ & $\{1 / 4,0,0\},\{1 / 4,1 / 4,1 / 4,0\}$ \\
$19: 00-19: 59$ & $\{1 / 4,1 / 4,1 / 4\},\{1 / 2,1 / 4,1 / 4,1 / 4\}$ & $\{1 / 4,0,0\},\{1 / 2,1 / 2,1 / 2,1 / 4\}$ & $\{1 / 4,0,0\},\{1 / 4,1 / 4,1 / 4,0\}$ \\
$20: 00-20: 59$ & $\{0,0,0\},\{3 / 4,3 / 4,3 / 4,3 / 4\}$ & $\{0,0,0\},\{1 / 2,1 / 2,1 / 2,1 / 2\}$ & $\{0,0,0\},\{1 / 4,1 / 4,1 / 4,1 / 4\}$ \\
$21: 00-21: 59$ & $\{0,0,0\},\{3 / 4,3 / 4,3 / 4,3 / 4\}$ & $\{0,0,0\},\{1 / 2,1 / 2,1 / 2,1 / 2\}$ & $\{0,0,0\},\{1 / 4,1 / 4,1 / 4,1 / 4\}$ \\
$22: 00-22: 59$ & $\{0,0,0\},\{3 / 4,3 / 4,3 / 4,3 / 4\}$ & $\{0,0,0\},\{1 / 2,1 / 2,1 / 2,1 / 2\}$ & $\{0,0,0\},\{1 / 4,1 / 4,1 / 4,1 / 4\}$ \\
$23: 00-23: 59$ & $\{0,0,0\},\{3 / 4,3 / 4,3 / 4,3 / 4\}$ & $\{0,0,0\},\{1 / 2,1 / 2,1 / 2,1 / 2\}$ & $\{0,0,0\},\{1 / 4,1 / 4,1 / 4,1 / 4\}$ \\
\hline
\end{tabular}

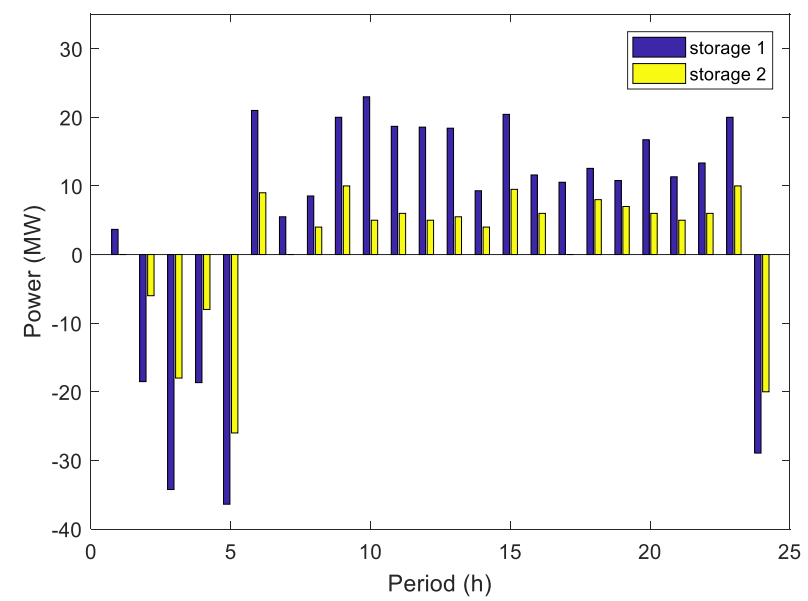

Fig.9 Storage process of BES with $\Delta=2$

Without loss of generality, uncertainty budget can be set the same value at whole time period, three typical uncertainty budgets $\Delta=3, \Delta=2, \Delta=1$ are chosen to take further analysis of the optimization performance and scheduling process. After optimization with different uncertainty budgets, the adjustable parameters $\gamma_{\mathrm{Ijt}}$ can be obtained at each time period, which are shown in Table.2. Convergence process with different uncertainty budgets are illustrated in Fig.5(a), 5(b) and 5(c), respectively, and the optimization process has a slower convergence as the uncertainty budget gets larger, it can also be found that both economic cost and emission rate achieve to converge within no more than 600 generations, it reflects that MOEA/D-GDDE can avoid premature problem to fall into local optima, and it also converges faster. Finally, those obtained optimal schemes with three typical uncertainty budgets $\Delta=3, \Delta=2, \Delta=1$ are shown in Figures 611 , where the output process of thermal units and charging and discharging process of energy storage are all illustrated. As shown in Figure 6, 8 and 10, it can be found that the thermal unit with larger capacity bear more system load during the scheduling process, power output of five thermal units can be almost sorted with order Unit $5>$ Unit $4>$ Unit 3>Unit $2>$ Unit 1 .

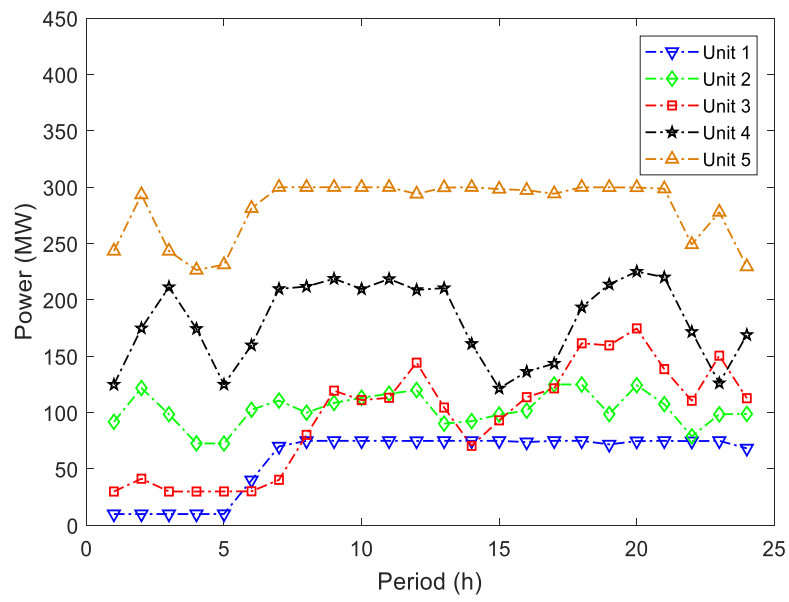

Fig.10 Thermal output process with $\Delta=1$ 


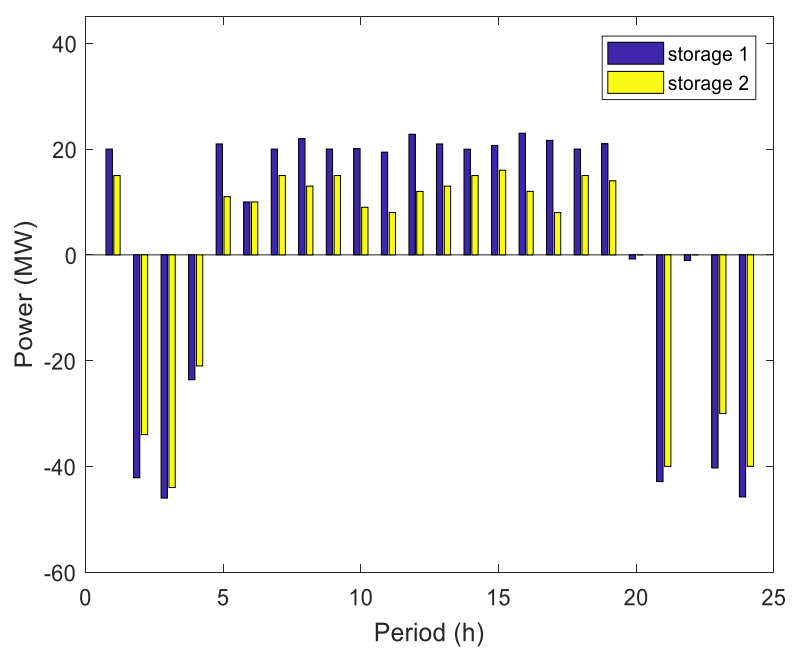

Fig.11 Storage process of BES with $\Delta=1$

According to above results and analysis, it can be concluded that probabilistic PBI based MOEA/D-GDDE method can deal with optimal operation of hybrid energy system and deduce the best operation scheme by the proposed two-step decision-making strategy.

\section{CONCLUSION}

The increasing penetration of a large number of intermittent energy resources presents a new challenge for the optimal operation of hybrid energy systems. To properly handle the uncertainty and to solve the probabilistic problems in the hybrid energy systems, this paper mainly has several conclusions as follows:

(1) Combined with uncertainty budget, scenarios based approach can properly deal with stochastic problem in hybrid energy system, adjustable parameters can decrease the conservation as well as decrease the potential risk.

(2) On the basis of MOEA/D framework, gradient descent based differential evolution can properly improve the optimization efficiency, the improved scaling parameter can be deduced to better fit the population evolution, which can further accelerate the convergence.

(3) The two-step decision-making approach can deduce robust interval of uncertainty budget, which can avoid the potential risk in hybrid energy system. Ultimately, best optimal scheme can be screened out from schemes set.

According to those simulation results, it reveals that the uncertainty budget can control the uncertainty of intermittent energy resources, MOEA/D-GDDE can improve the optimization efficiency and two-step decisionmaking strategy can ensure the robustness of the operation of the hybrid energy system.

\section{ACKNOWLEDGEMENT}

This work is supported by National natural science key fund (NO.61533010), National natural fund (NO.61503199).

\section{REFERENCES}

[1] J. Zahavi and L. Eisenberg, "Economic-environmental power dispatch," IEEE Trans Syst., Man, Cybern., vol. 5, no. 5, pp. 485-489, 1985.

[2] T. F. Robert, A. H. King, C. S. Harry, Rughooputh, and K. Deb, "Evolutionary multi-objective environmental/economic dispatch: Stochastic versus deterministic approaches," KanGAL, Rep. 2004019, pp.1-15, 2004.

[3] K. Deb, A. Pratap, S. Agarwal, and T. Meyarivan, "A fast and elitistmultiobjective genetic algorithm: NSGA-II,” IEEE Trans. Evol. Comput.,vol. 6, no. 2, pp. 182-197, Apr. 2002.

[4] M. A. Abido, "A niched Pareto genetic algorithm for environmental/economic power dispatch," Electr. Power Syst. Res., vol. 25, no. 2, pp.97-105, 2003.

[5] M. A. Abido, "Environmental/economic power dispatch using multiobjective evolutionary algorithms," IEEE Trans. Power Syst., vol. 18, no. 4, pp. 1529-1537, Nov. 2003.

[6] Shubham Agrawal, B. K. Panigrahi, and Manoj Kumar Tiwari,"Multiobjective Particle Swarm Algorithm With Fuzzy Clustering for Electrical Power Dispatch,"IEEE Trans. Evol. Comput., vol. 12, no. 5, pp. 529-541, 2008.

[7] Huifeng Zhang, Dong Yue, Xiangpeng Xie, Songlin Hu, Shengxuan Weng, "Multi-elite guide hybrid differential evolution with simulated annealing technique for dynamic economic emission dispatch,"Applied Soft Computing,Vol.34, pp. 312-323, 2015.

[8] D. B. Das and C. Patvardhan, "New multi-objective stochastic search technique for economic load dispatch," IEE Proc. Gen., Trans. Distrib., vol. 145, no. 6, pp. 747-752, 1998.

[9] A. Zhou et al., "Multiobjective evolutionary algorithms: A survey of the state of the art," Swarm Evol. Comput., vol. 1, no. 1, pp. 32-49, 2011.

[10] Arash Asrari, Saeed Lotfifard, and Mohammad S. Payam, "Pareto Dominance-Based Multiobjective Optimization Method for Distribution Network Reconfiguration," IEEE Transactions on smart grid.,vol. 7, no. 3, pp. 1401-1410, 2016.

[11] E. Zitzler, M. Laumanns, and L. Thiele, "SPEA2: Improving the strength Pareto evolutionary algorithm," Comput. Eng. Netw. Lab., Swiss Fed. Inst. Technol., Zurich, Switzerland, Tech. Rep. 103, 2001.

[12] E. Zitzler and S. Künzli, "Indicator-based selection in multiobjective search," in Parallel Problem Solving From Nature-PPSN VIII Berlin, Germany: Springer, 2004, pp. 832-842.

[13] N. Beume, B. Naujoks, and M. Emmerich, "SMS-EMOA: Multiobjective selection based on dominated hypervolume," Eur. J. Oper. Res., vol. 181, no. 3, pp. 1653-1669, 2007.

[14] T. Murata, H. Ishibuchi, and M. Gen, "Specification of genetic search directions in cellular multi-objective genetic algorithms," in Evolutionary Multi-Criterion Optimization. Berlin, Germany: Springer, 2001, pp. 82-95.

[15] Q. Zhang and H. Li, "MOEA/D: A multiobjective evolutionary algorithm based on decomposition," IEEE Trans. Evol. Comput., vol. 11, no. 6, pp. 712-731, Dec. 2007.

[16] I. Giagkiozis, R. C. Purshouse, and P. J. Fleming, "Generalized decomposition," in Evolutionary Multi-Criterion Optimization, vol. 7811. Berlin, Germany: Springer, 2013, pp. 428-442.

[17] Qi Kang, Xinyao Song, MengChu Zhou, Li Li, "A Collaborative Resource Allocation Strategy for Decomposition-Based Multiobjective Evolutionary Algorithms," IEEE Transactions on Systems, Man, and Cybernetics: Systems, 2018, doi: 10.1109/TSMC.2018.2818175.

[18] Luping Wang, Qingfu Zhang, Aimin Zhou, Maoguo Gong, and Licheng Jiao, "Constrained Subproblems in a Decomposition-Based Multiobjective Evolutionary Algorithm," IEEE Trans. Evol. Comput., vol. 20, no. 3, pp. 475-480, June. 2016.

[19] Xiaobing Kong, Xiangjie Liu, Lele Ma, Kwang Y. Lee, "Hierarchical Distributed Model Predictive Control of Standalone Wind/Solar/Battery Power System," IEEE Transactions on Systems, Man, and Cybernetics: Systems, 2019, DOI: doi=10.1109/TSMC.2019.2897646. 
[20] Chunxia Dou, Dong Yue, Josep M. Guerrero, "Multiagent SystemBased Event-Triggered Hybrid Controls for High-Security Hybrid Energy Generation Systems, " IEEE Transactions on Industrial Informatics, Vol.13, no.2, pp.584-594, 2017.

[21] Haghifam MR, Falaghi H, Malik OP., "Risk-based distributed generation placement," IET Generation Transmission and Distribution, Vol.2, pp. 252-260, 2008.

[22] Cong Liu, Audun Botterud, Zhi Zhou, Pengwei Du, "Fuzzy Energy and Reserve Co-optimization with High Penetration of Renewable Energy," IEEE Trans. on Sustainable Energy, Vol. 8, no. 2, pp. 782791, 2017.

[23] C. Zhao, J. Wang, J. Watson, Y. Guan, "Multi-stage robust unit commitment considering wind and demand response uncertainties," IEEE Trans. Power Syst., Vol. 28, pp. 2708-2717, 2013.

[24] álvaro Lorca, and Xu Andy Sun, “Adaptive Robust Optimization With Dynamic Uncertainty Sets for Multi-Period Economic Dispatch Under Significant Wind,'IEEE Trans. Power Syst.,Vol.30, no.4, pp. 1702-1713, 2015.

[25] B. Liang and J. Liao, "A fuzzy-optimization approach for generation scheduling with wind and solar energy systems," IEEE Trans. Power Syst., Vol. 22, pp. 1665-1674, 2007.

[26] Y. Liu, "Convergent results about the use of fuzzy simulation in fuzzy optimization problems," IEEE Trans. Fuzzy Syst., Vol. 14, pp. 295-304, 2006.

[27] Qipeng P. Zheng, Jianhui Wang, Andrew L. Liu, "Stochastic Optimization for Unit Commitment-A Review," IEEE Trans. Power Syst.,Vol.30, no.4, pp. 1913-1924, 2015.

[28] Chunhua Peng, Peng Xie, Lei Pan, and Rong Yu,"Flexible Robust Optimization Dispatch for Hybrid Wind/Photovoltaic/Hydro/Thermal Power System,"IEEE Transactions on Smart Grid, Vol. 7, no. 2, pp.751-762, 2016.

[29] Hao Ming, Le Xie, Marco Campi, Simone Garatti, and P. R. Kumar, "Scenario-based Economic Dispatch with Uncertain Demand Response," IEEE Transactions on Smart grid, vol, 10, no. 2, pp. 1858-1868, 2019.

[30] Aghaei J, Niknam T, Azizipanah-Abarghooee R, Arroyo JM, "Scenario-based dynamic economic emission dispatch considering load and wind power uncertainties,"International Journal of Electrical Power and Power System, Vol.47, pp. 351-367, 2013.

[31] Luping Wang, Qingfu Zhang, Aimin Zhou,Maoguo Gong, and Licheng Jiao,"Constrained Subproblems in a Decomposition-Based Multiobjective Evolutionary Algorithm,"IEEE Transactions on Evolutionary Computation, Vol. 20, no. 3, pp. 475-480, 2016.

[32] Huifeng Zhang, Dong Yue, Xiangpeng Xie, Chunxia Dou, Feng Sun, "Gradient decent based multi-objective cultural differential evolution for short-term hydrothermal optimal scheduling of economic emission with integrating wind power and photovoltaic power," Energy, Vol.122 pp. 1-19, 2017.

[33] Yutao Qi, Xiaoliang Ma, Fang Liu, Licheng Jiao, Jianyong Sun, Jianshe Wu, "MOEA/D with adaptive weight adjustment," Evol. Comput.,vol. 22, no. 2, pp. 231-264, 2014.

[34] Bittanti, S., Campi, M. C., \& Prandini, M. How many experiments are needed to adapt? In A. Chiuso, A. Ferrante, \& S. Pinzoni (Eds.), Modeling, estimation and control. Festschrift in honor of Giorgio Picci on the occasion of his sixty-fifth birthday (pp. 7-17). SpringerVerlag, 2007.

[35] Prandini, M., \& Campi, M. C. Scenario-based control: A new approach to constrained control design. Technical report, University of Brescia, 2009.

[36] Shouyong Jiang and Shengxiang Yang, "An Improved Multiobjective Optimization Evolutionary Algorithm Based on Decomposition for Complex Pareto Fronts," IEEE Transactions on Cybernetics, Vol.46, No.2, pp.421-437, 2016.

[37] Moayed Daneshyari,and Gary G. Yen, “Cultural-Based Multiobjective Particle Swarm Optimization,"IEEE Transactions on systems, man, and cybernetics-Part B: cybernetics, Vol.41, no.2, pp. 553-567, 2011.

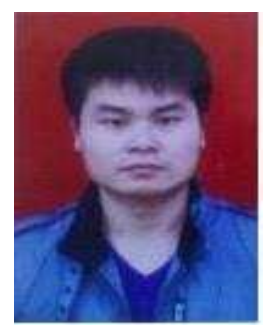

Huifeng Zhang received Ph.D. degree from Huazhong University of Science and Technology, Wuhan, China, in 2013. From 2014 to 2016, he was a Post-Doctoral Fellow with the Institute of Advanced Technology, Nanjing University of Posts and Telecommunications, Nanjing, China. From 2017 to 2018, he was granted as visiting research fellow by China Scholarship Council to study in Queen's University Belfast and University of Leeds, UK. He is currently an Associate Professor at the Institute of Advanced Technology, Nanjing University of Posts and Telecommunications, Nanjing, China. His current research interest includes electrical power management, optimal operation of power system, distributed optimization, and multi-objective optimization.

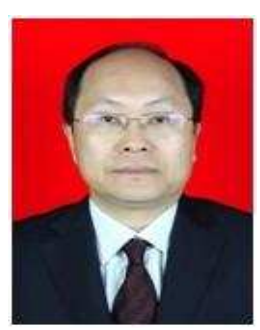

Dong Yue received the Ph.D. degree from the South China University of Technology, Guangzhou, China, in 1995. He is currently a Professor and the Dean with the Institute of Advanced Technology, Nanjing University of Posts and Telecommunications, Nanjing, China, and also a Changjiang Professor with the Department of Control Science and Engineering, Huazhong University of Science and Technology, Wuhan, China. His current research interests include analysis and synthesis of networked control systems, multiagent systems, optimal control of power systems, and internet of things. He has published over 100 papers in international journals, domestic journals, and international conferences. Prof. Yue is currently an Associate Editor of the IEEE Control Systems Society Conference Editorial Board and International Journal of Systems Science.

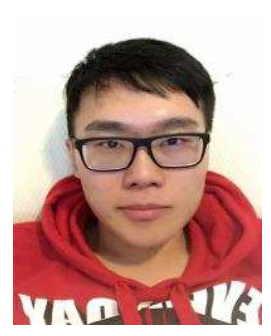

Wenbin Yue received his B.S degree in 2013 and M.S. degree in 2015, both in information technology from the Queensland University of Technology, Brisbane, Australia. He is currently pursuing the $\mathrm{Ph} . \mathrm{D}$. degree in computer science at Brunel University London, London, UK. His research interests include machine learning, recommendation system and big data analysis.

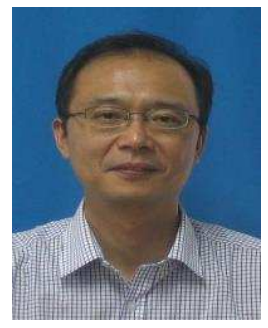

Kang Li (M'05-SM'11) received the B.Sc. degree in Industrial Automation from Xiangtan University, Hunan, China, in 1989, the M.Sc. degree in Control Theory and Applications from Harbin Institute of Technology, Harbin, China, in 1992, and the Ph.D. degree in Control Theory and Applications from Shanghai Jiaotong University, Shanghai, China, in 1995. He also received D.Sc. degree in Engineering from Queen's University Belfast, UK, in 2015. He currently holds the Chair of Smart Energy Systems at the University of Leeds, UK. His research interests cover nonlinear system modelling, identification, and control, and artificial intelligence, with substantial applications to energy and power systems, smart grid, electric vehicles, railway systems, and energy intensive manufacturing processes.

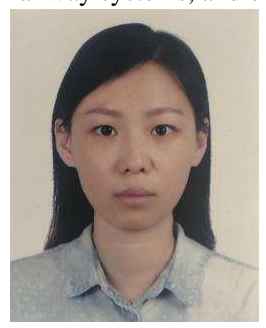

Mingjia Yin received the B.E. degree in electrical engineering from Nanjing University of Posts and Telecommunication, Jiangsu, China in 2011 and the M.Sc. degree from University of Bristol, U.K. in 2012 , respectively. She is currently pursuing the $\mathrm{Ph} . \mathrm{D}$ degree with the school of electronic \& electrical Engineering, University of Leeds, U.K. Her current research interests include power systems operation and optimisation. 